\title{
XRCC1 and DNA polymerase $\beta$ in cellular protection against cytotoxic DNA single-strand breaks
}

\author{
Julie K Horton ${ }^{1}$, Mary Watson ${ }^{2}$, Donna F Stefanick ${ }^{1}$, Daniel T Shaughnessy ${ }^{2}$, Jack A Taylor ${ }^{2}$, Samuel H Wilson ${ }^{1}$ \\ ${ }^{1}$ Laboratory of Structural Biology and ${ }^{2}$ Laboratory of Molecular Carcinogenesis, NIEHS, National Institutes of Health, Research \\ Triangle Park, NC 27709, USA
}

Single-strand breaks (SSBs) can occur in cells either directly, or indirectly following initiation of base excision repair (BER). SSBs generally have blocked termini lacking the conventional 5'-phosphate and 3'-hydroxyl groups and require further processing prior to DNA synthesis and ligation. XRCC1 is devoid of any known enzymatic activity, but it can physically interact with other proteins involved in all stages of the overlapping SSB repair and BER pathways, including those that conduct the rate-limiting end-tailoring, and in many cases can stimulate their enzymatic activities. $\mathrm{XRCC}^{--}$mouse fibroblasts are most hypersensitive to agents that produce DNA lesions repaired by monofunctional glycosylase-initiated BER and that result in formation of indirect SSBs. A requirement for the deoxyribose phosphate lyase activity of DNA polymerase $\beta$ ( $p o l \beta)$ is specific to this pathway, whereas pol $\beta$ is implicated in gap-filling during repair of many types of SSBs. Elevated levels of strand breaks, and diminished repair, have been demonstrated in MMStreated $\mathrm{XRCC1}^{--}$, and to a lesser extent in $\mathrm{pol} \mathrm{f}^{--}$cell lines, compared with wild-type cells. Thus a strong correlation is observed between cellular sensitivity to MMS and the ability of cells to repair MMS-induced damage. Exposure of

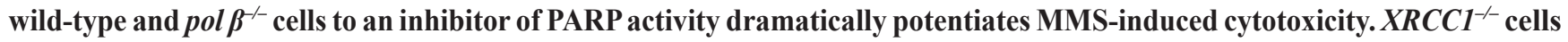
are also sensitized by PARP inhibition demonstrating that PARP-mediated poly(ADP-ribosyl)ation plays a role in modulation of cytotoxicity beyond recruitment of XRCC1 to sites of DNA damage.

Keywords: XRCC1, DNA polymerase $\beta$, single-strand break repair, base excision repair, PARP inhibition Cell Research (2008) 18:48-63. doi: 10.1038/cr.2008.7; published online 1 January 2008

\section{Introduction}

Cells have evolved intricate DNA repair mechanisms to circumvent genomic instability. Thousands of spontaneous single-strand breaks (SSBs) occur in cellular DNA each day [1] and, if they persist, can convert to potentially lethal double-strand breaks (DSBs). Accordingly, highly efficient and diverse mechanisms for SSB repair (SSBR) have evolved (Table 1). SSBs commonly have damaged or blocked termini that lack the conventional 5'-phosphate and the 3 '-hydroxyl required for polymerase activity and strand ligation. Thus, further processing of blocked DNA ends is required prior to DNA synthesis (3'-end-tailoring) and ligation (5'-end-tailoring), and such tailoring of blocked termini is frequently the rate-limiting step in a repair cascade $[2,3]$.

Correspondence: Samuel H Wilson

Tel: +919-541-3201; Fax: +919-541-3592

E-mail: wilson5@niehs.nih.gov

\section{Repair of IR-induced DNA damage}

Endogenous sources of SSBs include attack by reactive oxygen and alkylating species, as well as breaks that arise from the inherent instability of DNA. Direct SSBs can also be induced after sugar damage and disintegration of the DNA backbone following absorption of ionizing radiation (IR), or through IR-mediated formation of reactive oxygen species (ROS) [4]. SSBs resulting from IR commonly have 3'-phosphate or 3'-phosphoglycolate groups that are substrates for apurinic/apyrimidinic endonuclease (APE) $[5,6]$ or the oculomotor apraxia type 1 gene product aprataxin [7] (Table 1). Additionally during repair of IR-induced SSBs, blocking groups can be removed by the bifunctional enzyme polynucleotide kinase (PNK) (3'-phosphate) [8] or by tyrosyl DNA phosphodiesterase (Tdp1) (3'-phosphoglycolate) [9, 10] (Table 1). When DNA ligases attempt to repair non-ligatable blocked ends induced by ROS, abortive intermediates are formed with an adenylate group bound to the 5'-phosphate. Aprataxin has a hydrolase activity able to release the adenylate groups and producing a 5'-phosphate [11]. 
Table 1 Repair of cellular SSBs

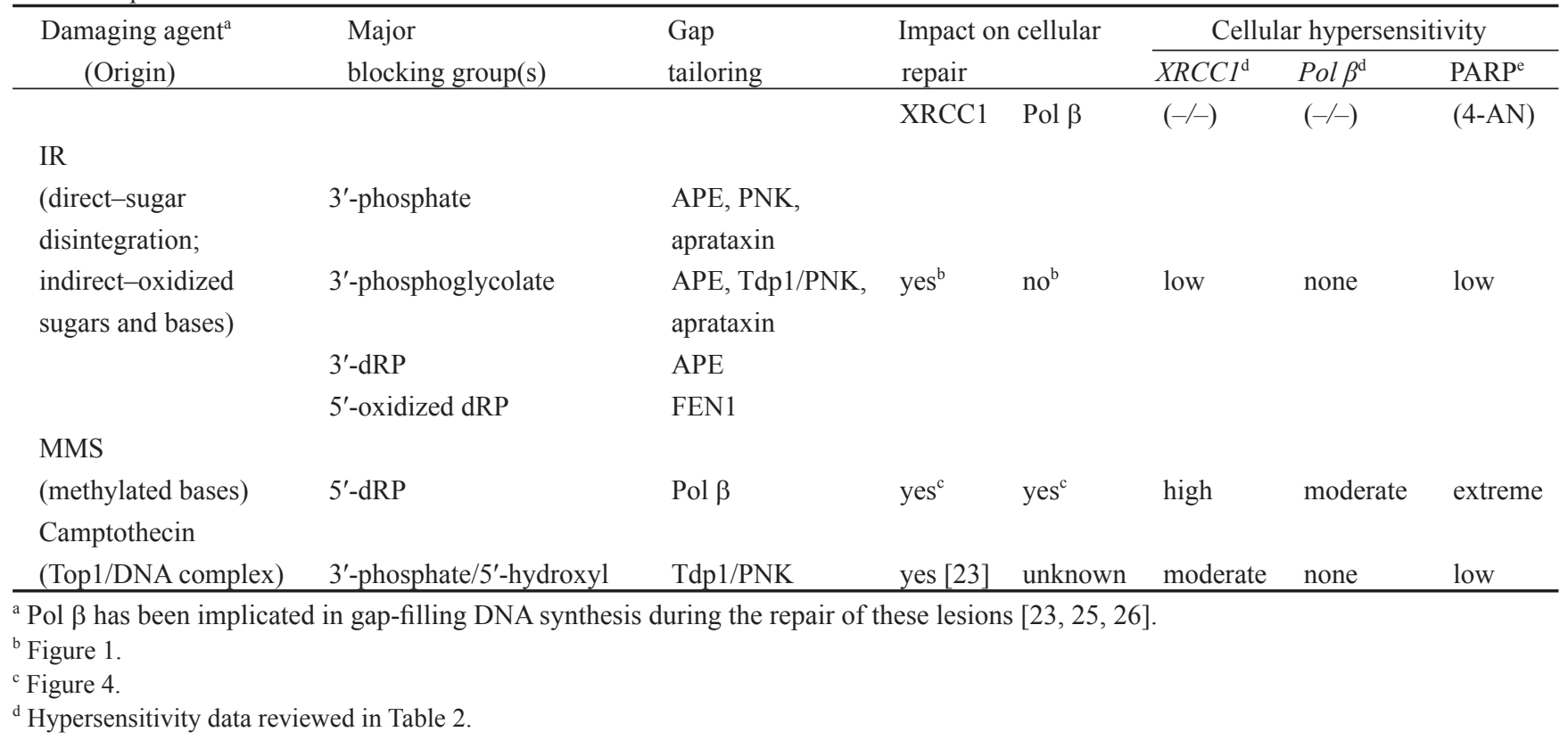

The initiation of BER of IR- and other ROS-mediated oxidative base damage can result in formation of indirect SSBs generated as intermediates of BER. In general, oxidized bases are excised by bifunctional glycosylases that have an associated AP lyase activity able to nick the DNA strand 3 ' to the abasic site following base removal. In the case of glycosylase-catalyzed $\beta$-elimination associated with 8-oxoguanine-DNA glycosylase (OGG1) for example [12], APE is required to remove the blocking 3'-deoxyribosephosphate (dRP) group prior to gap-filling synthesis [5] (Table 1). Abasic site cleavage by glycosylase-associated $\beta, \delta$-elimination, for example by NEIL1 or $2[13,14]$, generates 3 '-phosphate termini that can be removed by PNK in an APE-independent repair pathway [15] (Table 1). Alternatively, the AP site can be 5'-incised by APE, circumventing the glysosylase-associated AP lyase step [16]. Oxidized abasic sites result in formation of 5'-oxidized $\mathrm{dRP}$ that can be removed by flap endonuclease 1 (FEN1) as part of the alternate long-patch BER sub-pathway [17] (Table 1).

\section{Monofunctional glycosylase-initiated BER}

Indirect SSBs similarly arise when BER is initiated by a monofunctional glycosylase. For example, $N$-methylpurine-DNA glycosylase (MPG) removes damaged bases (e.g. $N 7$-alkyl guanine) occurring following exposure to simple alkylating agents such as methyl methanesulfonate (MMS). The resulting abasic site undergoes 5 '-strand incision by APE. Removal of the $5^{\prime}$-dRP blocking group is catalyzed by the dRP lyase activity of DNA polymerase $\beta$ (pol $\beta$ ), and, in the preferred single-nucleotide BER sub-pathway, pol $\beta$ also performs single-nucleotide gap-filling synthesis (Table 1) [2]. When a modified dRP group is not a substrate for the lyase activity, pol $\beta$-dependent strand displacement synthesis, in conjunction with FEN1-mediated flap cleavage, can conduct long patch BER $[18,19]$. It should be noted that pol $\beta$-independent single-nucleotide and long patch BER pathways have also been well documented [20,21].

\section{Formation of topoisomerase I-DNA complex}

Another source of SSBs is the transient single-strand nicking by topoisomerase I (Top1) ahead of DNA replication. Under normal conditions, Top1 religates the breaks once relaxation of DNA supercoiling has occurred. This religation process is inhibited by Top1 inhibitors such as camptothecin, resulting in trapping of Top1 cleavage complexes and formation of protein-linked SSBs [22]. Following processing by the proteosome, Tdp1-mediated hydrolysis removes the truncated form of Top1 that is covalently linked to DNA. This produces SSBs with a 3'-phosphate and a 5'-hydroxyl that can be removed by PNK, and in some cases subsequently extended by pol $\beta$ prior to ligation (Table 1) $[9,23]$. Cytotoxic DSBs arise by collision between replication forks and the stabilized Top 1 cleavage complexes [24].

\section{Role of pol $\beta$ in DNA repair}

The $\mathrm{X}$-family polymerase, pol $\beta$, is organized into two distinct domains, a $31-\mathrm{kDa}$ polymerase domain and an 8 -kDa dRP lyase domain. The polymerase activity of 
pol $\beta$ has been implicated in gap-filling synthesis during repair of all the DNA lesions described above [23, 25, 26] (Table 1), but this activity is generally not rate-determining in repair. In contrast, the dRP lyase activity normally contributed by pol $\beta$ in cells is essential and rate-limiting during monofunctional glycosylase-initiated BER [2]. The hallmark MMS-hypersensitivity phenotype of pol $\beta$ deficiency is thought to be a result of failure to repair the cytotoxic 5'-dRP intermediate of BER $[27,28]$.

\section{Role of XRCC1 in DNA repair}

$\mathrm{X}$-ray cross-complementing group 1 (XRCC1) is a 70$\mathrm{kDa}$ protein comprising three functional domains; an $\mathrm{N}$ terminal DNA binding domain, a centrally located BRCT I and a C-terminal BRCT II domain. It has no known enzymatic activity. Since it specifically interacts with nicked and gapped DNA in vitro [29, 30], and rapidly and transiently responds to DNA damage in cells, it may serve as a strand-break sensor [31,32]. However, complementation experiments in XRCC1-deficient $\mathrm{CHO}$ cells suggest that the interaction of XRCC1 with DNA is not critical for efficient SSBR .

In addition, since XRCC1 interacts with many proteins known to be involved in BER and SSBR, it has been proposed that XRCC1 functions as a scaffold protein able to coordinate and facilitate the steps of various DNA repair pathways $[32,34]$. For example, XRCC1 interacts with several DNA glycosylases involved in repair of both oxidative and alkylated base lesions, and stimulates their activity $[35,36]$. XRCC1 also interacts with the N-terminal of APE stimulating both its AP endonuclease and 3 '-dRPase activities [37]. Binding of XRCC1 to PNK enhances its capacity for damage discrimination, and binding of XRCC1 to DNA enables displacement of PNK from the phosphorylated product [34] thus accelerating SSBR of damaged DNA [38]. XRCC1 associates with Tdp1 and enhances its activity required for repair of Top1-associated SSBs. It may act to recruit Tdp1 to these damaged sites [23]. Biochemical and NMR experiments have demonstrated protein-protein interaction between the $\mathrm{N}$-terminal domain of XRCC1 and the polymerase domain of pol $\beta$ [39-42]. Additionally, stabilization of DNA ligase III $\alpha$ is dependent on its interaction with the BRCT II domain of XRCC1 [43]. Aprataxin also interacts with XRCC1 and functions to maintain XRCC1 stability, thus further linking the neurological degeneration associated with ataxia to an inefficiency of SSBR [44-46].

\section{Poly(ADP-ribose)-mediated recruitment to repair foci}

Poly(ADP-ribose) polymerase (PARP)s- 1 and 2, members of a family of at least 18 proteins with poly(ADPribosyl)ating activity, interact with the BRCT I domain of XRCC1 [47, 48]. Upon detection of DNA nicks and binding to damaged DNA, the activity of PARP-1 in particular is rapidly stimulated and, using $\mathrm{NAD}^{+}$as substrate, it poly(ADP-ribosyl) ates multiple proteins including itself [49]. As a consequence of self poly(ADP-ribosyl)ation, PARP-1 loses affinity for DNA and is released from its binding site permitting access of repair proteins $[50,51]$. Binding and activation of PARP-1 may function to sequester other DNA repair proteins to sites of SSBs. For example, XRCC1 preferentially interacts with automodified PARP-1 $[47,52]$. In this way, activated PARP-1 recruits XRCC1 to sites of oxidative and methylated DNA damage suggesting that formation of repair foci may be mediated by poly(ADP-ribose) (PAR) [53, 54]. In addition, XRCC1 is a substrate for PARP-1-mediated poly(ADP-ribosyl)ation thus confirming the functional interaction between these two proteins [47]. DNA ligase III $\alpha$ associates with poly(ADP-ribosyl)ated PARP-1 providing another possible mechanism for recruitment of the XRCC1-ligase III $\alpha$ complex to sites of SSBs [55]. Consistent with the idea that these proteins together are essential for SSBR, PARP-1, like XRCC1, also interacts with aprataxin [45].

\section{Maintenance of genomic stability}

Both XRCC1 and pol $\beta$ play a significant role in maintaining chromosomal stability. An elevated level of sister chromatid exchange, widely used as an indicator of genetic damage, is characteristic of XRCC 1 and pol $\beta$ deficiency [56-59]. Genomic instability is proposed to be a factor in tumor initiation [60]. Polymorphisms of XRCC1, and possibly pol $\beta$, have been associated with a higher risk of cancer [61-64]. Approximately 30\% of human tumors express pol $\beta$ variants, some of which are associated with a mutator phenotype (summarized in [65]), and overexpression of pol $\beta$ is a common event in tumorigenesis [66]. It is therefore interesting to compare and contrast the phenotypes and repair defects associated with the absence of XRCC1 and pol $\beta$ in cells.

\section{Available XRCC1- and pol $\beta$-deficient cell lines}

The XRCC1-mutant strains of Chinese hamster ovary (CHO) cells, EM7 and EM9, were isolated from the parental strain, AA8, based on hypersensitivity to the alkylating agent ethyl methanesulfonate (EMS) [67]. Alternate mutant strains (EM-C11 and EM-C12) also lacking functional XRCC1 were similarly isolated from CHO-9 cells [57, 68]. Defects in EM9 cells could be corrected by transfection with a human or mouse DNA repair gene designated $\mathrm{XRCC} 1$ since it was the first mammalian gene isolated that affects cellular sensitivity to X-rays [69-71]. No full length $\mathrm{XRCC} 1$ protein nor truncated forms could be detected in 
any of the mutant $\mathrm{CHO}$ cell extracts $[68,72]$, and sequence analysis revealed debilitating point mutations in the cDNAs of all the mutant cell lines [68]. Alterations in the encoded amino acid sequence are presumed to affect protein folding and protein-protein interactions, or result in prevention of translation of full-length functional protein [68].

Gene targeting in mice to produce a null mutation in the XRCC1 gene resulted in early embryonic lethality and accumulation of endogenous DNA damage [73]. Creation of XRCC1-p53 double knock-out embryos resulted in a delay of lethality, but embryos failed to survive to term. However, it was possible to isolate $\mathrm{XRCCl}^{-/-}$mouse embryonic fibroblasts [73]. Both the embryonic lethality, and the hypersensitivity to DNA damage observed in XRCC1-deficient cells, could be reversed by even low-level expression of XRCC1 protein $[73,74]$.

A homozygous pol $\beta$ gene deletion similarly resulted in embryonic lethality [75] suggesting there is a requirement for BER and/or SSBR during early mouse development. Mouse embryonic fibroblasts could be established from these homozygous deletion mice at 10 days gestation and were transformed by expression of the SV40 large-T antigen [26]. In another mouse system, targeted disruption of the pol $\beta$ gene resulted in growth retardation, developmental defects of the nervous system and death from respiratory failure immediately after birth [76]. There was dramatically decreased neuronal apoptosis in a double knock-out model ( pol $\beta^{--}, p 53^{---}$), but developmental defects were still evident and the mice died shortly after birth [77].

\section{Characteristics of XRCC1- and pol $\beta$-deficient cells: hypersensitivity and repair deficiency following treat- ment with IR}

The CHO cell mutant EM9 demonstrates sizeable hypersensitivity to the alkylating agent EMS, but is reported to be only 2-fold hypersensitive to X-rays [56] (reviewed in Table 2). Another CHO cell strain showed even lesser hypersensitivity to IR [57]. Consistent with results obtained in XRCC1-deficient $\mathrm{CHO}$ cells, XRCC1 genetic deficiency in mouse fibroblasts also resulted in minimal hypersensitivity to IR (Figure 1A) [73]. In addition, no

Table 2 DNA damage-induced hypersensitivity phenotypes associated with XRCC1 and pol $\beta$ deficiency

\begin{tabular}{|c|c|c|c|c|c|}
\hline \multirow[t]{2}{*}{ DNA damage } & \multicolumn{2}{|c|}{ XRCC1 deficiency ${ }^{\mathrm{a}}$} & \multirow[t]{2}{*}{ References } & \multirow{2}{*}{$\begin{array}{c}\text { Pol } \beta \text { deficiency }{ }^{\mathrm{a}} \\
\quad P o l \beta^{-}\end{array}$} & \multirow[t]{2}{*}{ References } \\
\hline & $\mathrm{CHO}$ cell mutant & $X R C C 1^{-/}$ & & & \\
\hline IR & $\leq 2$ & $<2^{\mathrm{b}}$ & {$[56,57,67,73,92]$} & none $^{\mathrm{b}}$ & {$[26,78]$} \\
\hline MMS & $7-12$ & 11 & {$[56,57,69,106]$} & 2.8 & {$[26,28,58,102]$} \\
\hline EMS & $6-12$ & $9-12^{\mathrm{b}}$ & {$[56,57,67,73,92]$} & 2.3 & {$[26,28]$} \\
\hline MNNG & $<2$ & $22^{\mathrm{b}}$ & {$[56,92]$} & 4.1 & {$[28,58]$} \\
\hline MNU & 2 & & {$[57]$} & 3.8 & {$[26,28]$} \\
\hline ENU & 2 & & [57] & 1.8 & {$[28]$} \\
\hline TMZ & & $15^{\mathrm{b}}$ & & 4.5 & [28] \\
\hline hmdUrd & & $18^{\mathrm{b}}$ & & 3.8 & [28] \\
\hline CldUrd & $6-16$ & & {$[69,92]$} & & \\
\hline Mitomycin C & $<2$ & & {$[56,57,95]$} & & \\
\hline Melphalan & none & & {$[94]$} & none & {$[58]$} \\
\hline Chlorambucil & none & & [94] & & \\
\hline Nitrogen mustard & none & & [95] & & \\
\hline DMM & & $9^{\mathrm{b}}$ & & $2.3^{\mathrm{b}}$ & \\
\hline DEM & & $5^{\mathrm{b}}$ & & $2.0^{\mathrm{b}}$ & \\
\hline Hydrogen peroxide & 2 & $<1^{\mathrm{b}}$ & [99] & 1.6 & {$[102,103]$} \\
\hline Peroxynitrite & & none $^{\mathrm{b}}$ & & 1.4 & {$[103]$} \\
\hline Bleomycin & & $<1^{\mathrm{b}}$ & & 2.0 & [103] \\
\hline Camptothecin & 4.5 & $6^{\mathrm{b}}$ & {$[104,111]$} & $1.1^{\mathrm{b}}$ & \\
\hline Etoposide & & $<1^{\mathrm{b}}$ & & & \\
\hline UV & $<2$ & none $^{\mathrm{b}}$ & {$[56,57]$} & none & {$[26,58,119]$} \\
\hline Cisplatin & none & none $^{\mathrm{b}}$ & {$[94,95]$} & none & {$[58,103]$} \\
\hline
\end{tabular}

${ }^{a}$ Fold hypersensitivity in XRCC1-and pol $\beta$-deficient cell lines compared with wild-type repair-proficient cells.

b This study. 
A

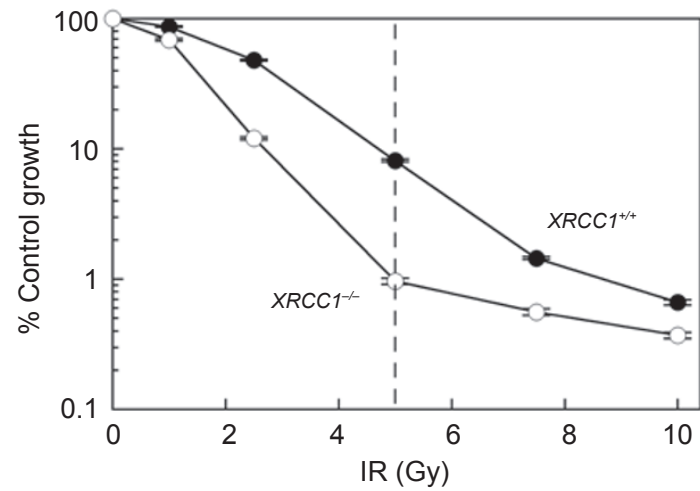

C

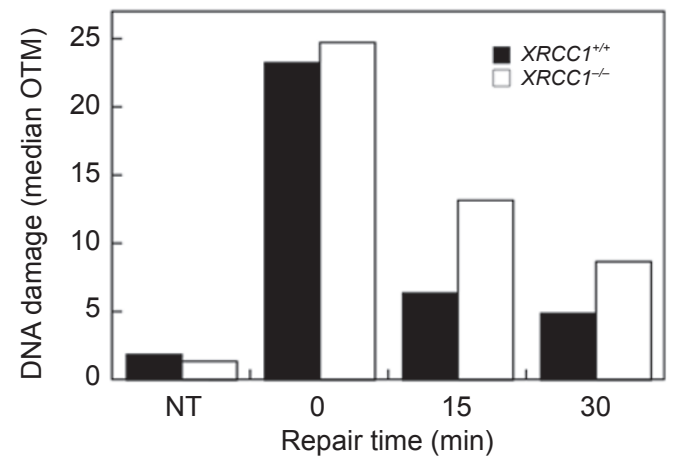

B
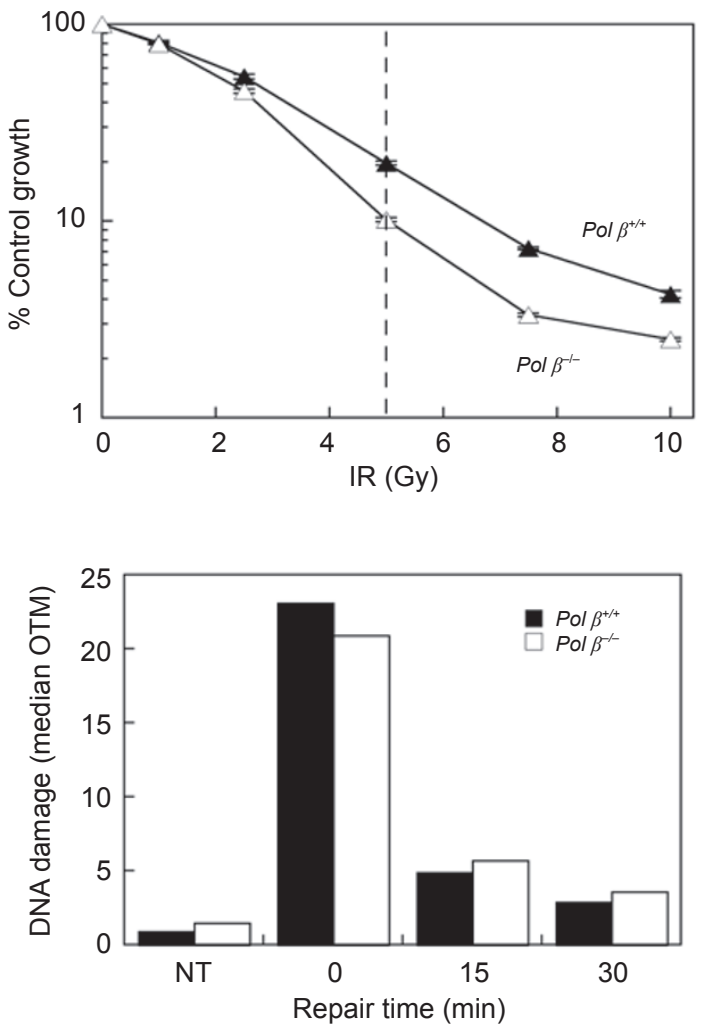

Figure 1 Survival of mouse embryonic fibroblasts following exposure to IR and repair of IR-induced DNA damage. (A) XRCC $1^{+/+}$ (closed circles) and $X R C C 1^{-/}$(open circles) and (B) $P o l ~ \beta^{+/+}$(closed triangles) and pol $\beta^{-/-}$cells (open triangles) were exposed to IR and survival was determined by growth inhibition assays as described [119]. The dashed line indicates the dose of IR used in the experiments presented in panels $\mathbf{C}$ and $\mathbf{D}$. Data are from representative experiments where the values are the mean \pm SEM of 4-5 determinations. (C and D) DNA damage (median OTM) was analyzed in non-treated cells (NT), and cells irradiated (5 Gy) then allowed to repair for 15 and $30 \mathrm{~min}$ as shown. The XRCC1 [73] and pol $\beta$ [26] cell lines have been described previously.

hypersensitivity was observed to the radiomimetic agent, bleomycin (Table 2). Similarly, significant hypersensitivity to IR was not observed in fibroblasts deficient in pol $\beta$ (Figure 1B) [26, 78].

Irradiation of cells has been shown to generate DSBs and SSBs (ratio of 1:25 [79]), that can be detected in individual cells by the alkaline comet assay [80, 81]. IR-mediated DSBs are generated from locally multiply damaged sites arising due to ionization tracks and radiolysis of water, and DSBs are believed to be responsible for most IR-induced lethality [82]. In addition, IR-induced modification of bases and sugars (ratio of oxidized bases:SSBs is 3:1 [79]) results in formation of DNA nicks and alkali-labile sites following initiation of BER. Repair of IR-induced DNA damage in wild-type $\mathrm{CHO}$ cells [70,83], as well as mouse fibroblasts, is extremely rapid (Figure 1C and 1D). A reduced rate of repair of DNA SSBs formed in irradiated XRCC1 mutant $\mathrm{CHO}$ cells has been identified by alkaline elution and the alkaline comet assay [56, 70, 83]. Similarly, plots of median Olive Tail Moment (OTM) [81] demonstrate there is a delay in repair of IR-induced damage in $\mathrm{XRCCl}^{-/-}$mouse fibroblast cells compared with wild-type cells following exposure to $5 \mathrm{~Gy}$ of irradiation (Figure 1C). Thus the comet assay data confirm that there is repair deficiency associated with the absence of XRCC1 protein.

$\mathrm{XRCC} 1$ has several roles in the repair of DSBs, as well as SSBs, thus making a repair deficiency of IR-induced DNA damage likely in the absence of XRCC1. For example, PNK interacts with CK2-phosphorylated XRCC1 [84], and XRCC1 is known to stimulate the activities of PNK required for end-processing during SSBR (Table 1) as well as during repair of DSBs by non-homologous end-joining (NHEJ) [85]. Further, a recently described PARP-1-dependent back-up pathway of NHEJ involves the XRCC1-ligase III $\alpha$ complex as well as PNK $[86,87]$. In addition, $\mathrm{XRCC} 1$ is known to interact with the catalytic subunit of DNA-dependent protein kinase (DNA-PK) via its BRCT I domain. DNA-PK facilitates recruitment of proteins required for NHEJ, and XRCC1 is phosphorylated by DNA-PK in response to IR-induced DNA damage 
[88], thus providing evidence for its involvement in DSB repair. Interestingly, repair measured in $\mathrm{XRCC1}^{-/-}$cells by the comet assay, although delayed, is still relatively fast ( $<65 \%$ repair of damage by $30 \mathrm{~min}$; Figure $1 \mathrm{C}$ ) and only a minimal IR hypersensitivity phenotype is observed (Figure 1A). It seems that $X R C C 1^{-/-}$cells have a significant capacity to repair IR-induced cytotoxic damage even in the absence of DSB repair mechanisms in which XRCC1 has been implicated.

In contrast to results obtained in XRCC1-deficient cells, a delay in rejoining of strand breaks in pol $\beta^{-/}$cells was not detected (Figure 1D). Thus, the absence of IR hypersensitivity in replicating pol $\beta^{-/}$cells (Figure 1B, Table 2 ) correlates well with these repair data. The simplest explanation for these results is that pol $\beta$ is not critical in cells for repair of IR-induced DNA damage (both cytotoxic and non-cytotoxic). Pol $\beta$ has been implicated in gap-filling during BER and SSBR, but not in repair of DSBs by homologous recombination or NHEJ. Inefficient repair of SSBs is expected to result in an increased incidence of DSBs, however, since pol $\beta$ is generally not needed for DNA gap-tailoring during the repair of oxidized bases and sugars, or SSBs (Table 1), overall repair may remain efficient in its absence. Alternatively, there might be robust mechanisms for repair of IR-induced DNA damage that, in the absence of pol $\beta$, can efficiently substitute for pol $\beta$-dependent pathways. A recent study has described IR hypersensitivity in non-dividing pol $\beta$ null cells suggesting that pol $\beta$-dependent repair is masked by alternate replication associated repair pathways in cycling cells [89].

\section{Characteristics of XRCC1- and pol $\beta$-deficient cells: hypersensitivity and repair deficiency following ex- posure to MMS}

Despite being named for their X-ray cross-complementing gene deficiency, $\mathrm{CHO}$ cells with mutated $\mathrm{XRCC} 1$ are significantly more sensitive to the monofunctional alkylating agents, EMS and MMS, than to IR [56]. Similarly, and in contrast to the low hypersensitivity observed for IR, $X R C C 1^{-/}$mouse fibroblasts are at least 10-fold more sensitive than $X R C C 1^{+/+}$cells to both EMS [73] and MMS (Table 2). Expression of wild-type XRCC1 protein complements the MMS and EMS hypersensitivity phenotype of both EM9 cells $[33,52,53,90,91]$ and $X R C C 1^{-/}$mouse fibroblasts [73] (Figure 2A). The high degree of EMS and MMS hypersensitivity indicates that XRCC1 is essential for resistance of cells to the cytotoxic effects of these simple
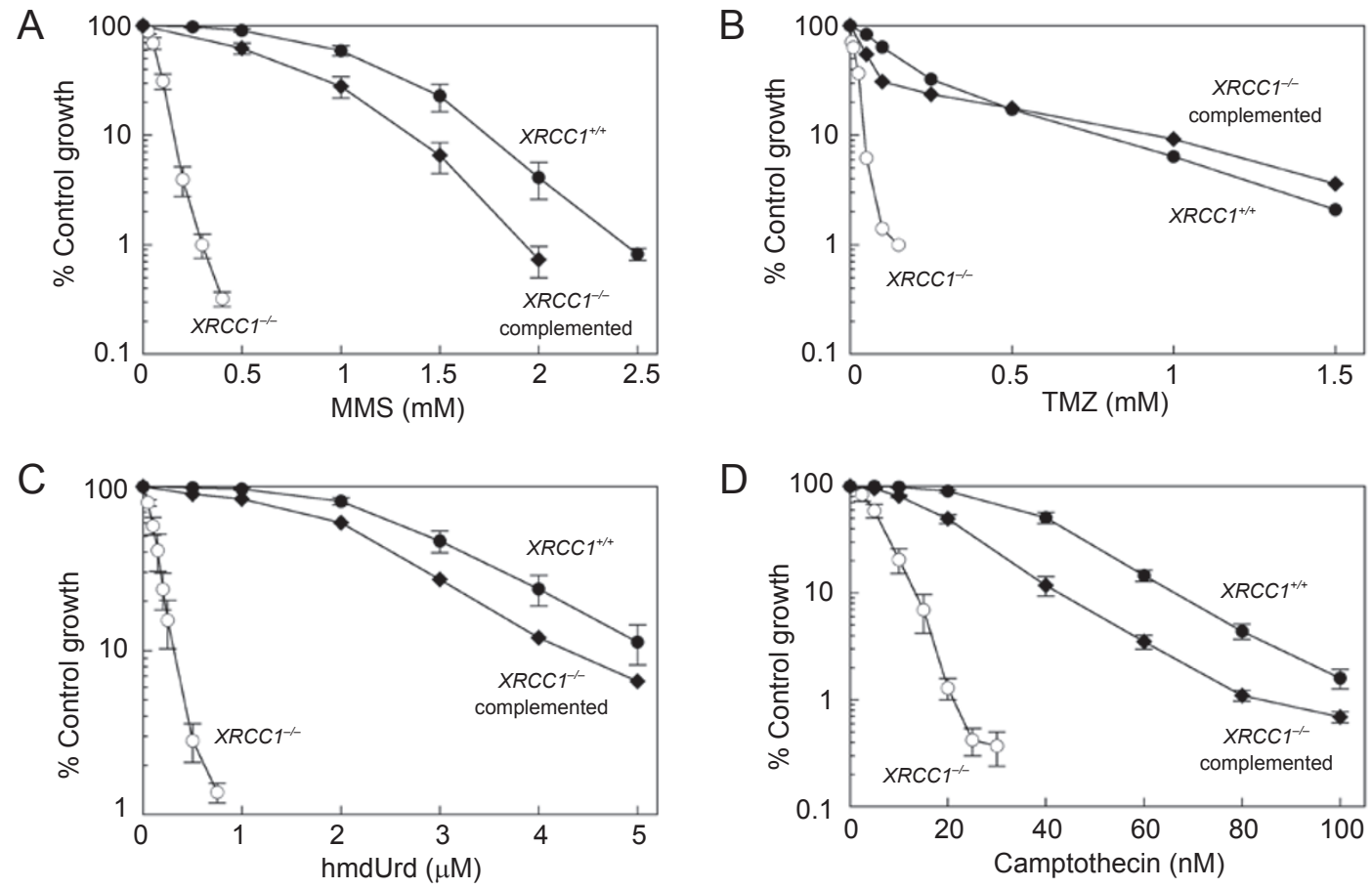

Figure 2 Complementation of $X R C C 1^{-/-}$hypersensitivity phenotypes by expression of the XRCC1 gene. XRCC1 ${ }^{+/+}$(closed circles) and $X R C C 1^{-/}$mouse embryonic fibroblasts (open circles) or $X R C C 1^{-/}$fibroblasts transfected with mouse $X R C C 1 \mathrm{cDNA}$ (closed diamonds) were treated with (A) MMS for $1 \mathrm{~h},(B) \mathrm{TMZ}$ for $4 \mathrm{~h},(\mathrm{C}) \mathrm{hmdUrd}$ for $24 \mathrm{~h}$, or (D) camptothecin for $24 \mathrm{~h}$. Cell sensitivity was determined by growth inhibition assays as described [119]. The cell lines have been described previously [73]. 


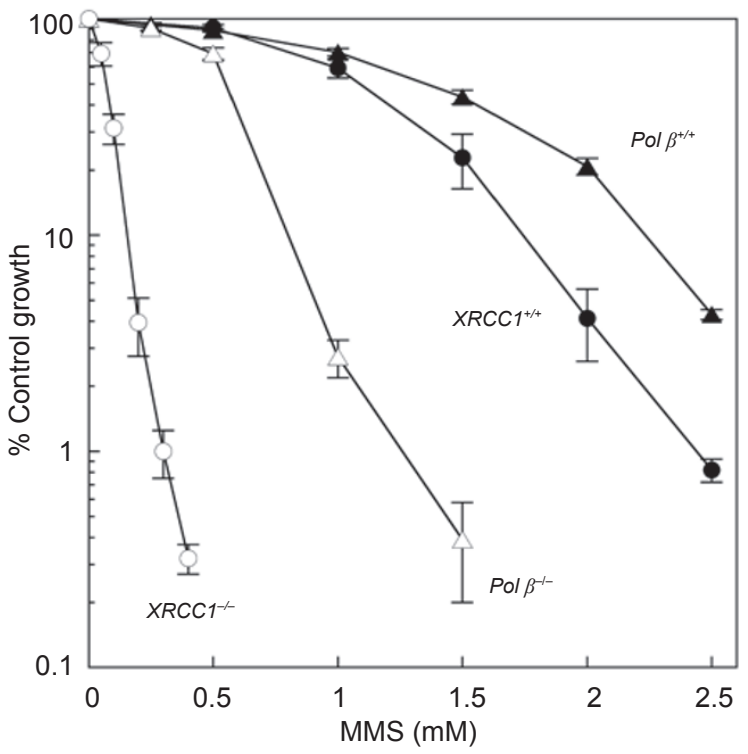

Figure 3 MMS hypersensitivity in $X R C C 1^{-/}$compared with pol $\beta^{-\alpha}$ mouse embryonic fibroblasts. Sensitivity of $X R C C 1^{-\alpha}$ (open circles) and $\mathrm{pol} \beta^{--\alpha}$ cells (open triangles) to a $1 \mathrm{~h}$ exposure to MMS is compared with that of the respective isogenic wild-type $\left(^{+/+}\right)$cell lines (closed symbols). Cell sensitivity was determined by growth inhibition assays as described [119]. The cell lines have been described previously [26, 73]. Data taken from ref. [106].

alkylating agents. Strikingly, for both of these agents, the hypersensitivity of $\mathrm{XRCCl}^{--}$cells is considerably greater than the 2-3-fold differential in sensitivity observed in $\mathrm{pol}$ $\beta^{+/+}$and pol $\beta^{-/}$cells (Figure 3, Table 2). The hypersensitivity of $\mathrm{pol} \beta^{-/}$mouse fibroblasts to monofunctional alkylating agents has been proposed to reflect accumulation of cytotoxic intermediates of BER in the absence of pol $\beta$-mediated repair [28]. The more profound hypersensitivity of $\mathrm{XRCC1}^{--}$cells suggests that XRCC1 may be required for efficient BER by both pol $\beta$-dependent and -independent repair pathways.

A defect in repair of MMS-induced SSBs has been demonstrated by the alkaline comet assay (which will detect cytotoxic abasic sites and SSB intermediates of BER) in XRCC1-deficient $\mathrm{CHO}$ cells [33, 52, 91]. Following a short exposure of mouse embryonic fibroblasts to ice cold MMS, higher levels of DNA damage were seen than found in control untreated cells (NT), but levels were similar in the paired isogenic repair-deficient and wild-type cell lines (Figure 4, panels A and B). The survival of the cells following this same MMS treatment protocol is also presented (Figure 4, panels $\mathrm{C}$ and D). In both XRCC1 and pol $\beta$ wildtype mouse fibroblasts, the level of DNA damage (median OTM) remained fairly constant during the repair incubation suggesting that the formation, and the repair, of strand breaks and alkali-labile sites are occurring at a similar rate (Figure 4, panels A and B). In contrast, elevated levels of DNA damage (median OTM) and diminished repair was observed in $\mathrm{XRCCl}^{--}$and, to a lesser extent, in $\mathrm{pol} \beta^{-/}$cell lines compared with wild-type cells (Figure 4, panels A and B). Since a good correlation is seen between the MMS sensitivity of the different mouse fibroblast lines and their ability to repair DNA damage arising following exposure to MMS (Figure 4), the results support the hypothesis that $X R C C 1^{-/}$cells, like pol $\beta^{--}$cells, are deficient in cellular BER of MMS-induced damage.

In the absence of pol $\beta$, cellular hypersensitivity to MMS is associated with a deficiency in the rate-limiting pol $\beta$-dependent dRP lyase activity, rather than its polymerase activity, in the predominant single-nucleotide BER pathway [27]. Perhaps XRCC1 in some way facilitates $5^{\prime}$-dRP removal by pol $\beta$ during monofunctional glycosylase-initiated BER, although such an effect has not been documented. XRCC1 and pol $\beta$ proteins are known to physically interact $[41,42]$, and there is a rapid but lesser accumulation of pol $\beta$ at sites of DNA base damage in cells in the absence of XRCC1 [31]. XRCC1 may also be required for accumulation of other proteins with dRP lyase activity (e.g., DNA polymerase $\lambda$ ). Since XRCC1deficient cells are more sensitive to MMS than are pol $\beta$ -deficient cells, XRCC1 clearly has a role in protection of cells against MMS-induced cytotoxicity in addition to mediating recruitment of pol $\beta$. In fact complementation of EM9 cells with a mutant XRCC1 (V86R) that disrupts the interaction with pol $\beta$ is known to result in significant correction of the MMS hypersensitivity phenotype [33]. The effects of XRCC1 may be additive since it can coordinate the entire BER pathway for MMS-induced DNA damage through protein-protein interactions and stimulation of the glycosylase, APE and ligase activities implicated in MMSinduced single-nucleotide BER [36, 37, 43]. Interestingly, expression in EM9 cells of an XRCC1 BRCT II mutant protein that does not interact with ligase III $\alpha$ is able to fully complement hypersensitivity to MMS in the absence of a stabilizing effect on ligase III $\alpha[90,91]$. Another possibility is that the protective role of XRCC1 is not entirely related to DNA repair, but that it modifies damage-dependent signaling resulting in cell death.

\section{Characteristics of XRCC1- and pol $\beta$-deficient cells: hypersensitivity to DNA damage requiring BER}

$X \mathrm{RCC}^{-/-}$cells are more hypersensitive to the $\mathrm{S}_{N} 1$ type methylating agent $N$-methyl- $N$ '-nitro- $N$-nitrosoguanidine (MNNG) (22-fold) than to the $\mathrm{S}_{N} 2$ type agent MMS (Table 2 ) whereas lesser (2-fold) hypersensitivity was described in EM9 cells [56, 92]. This discrepancy may be related to 
A

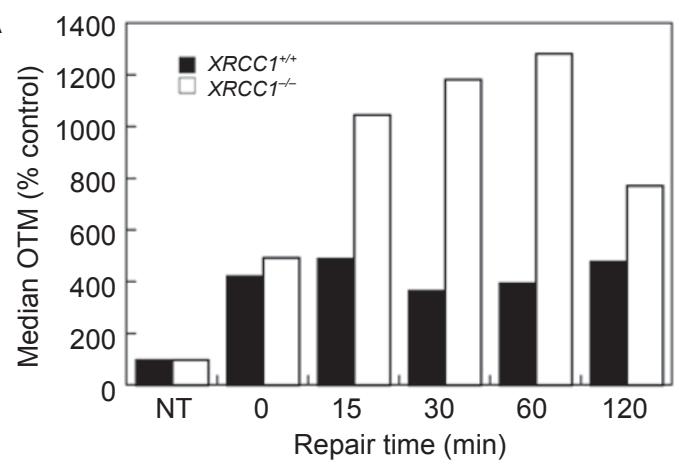

C

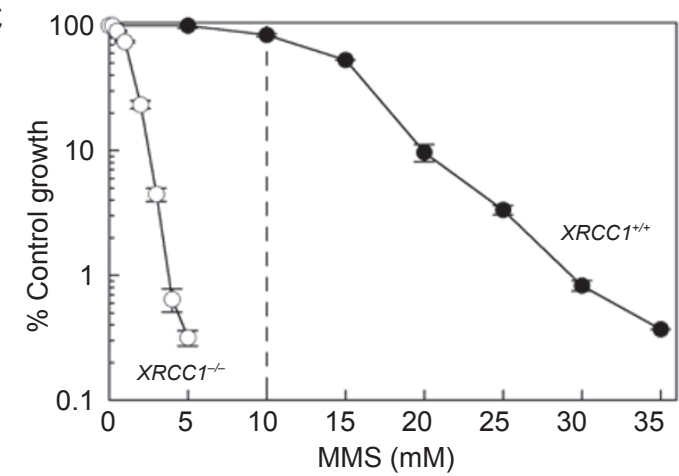

B

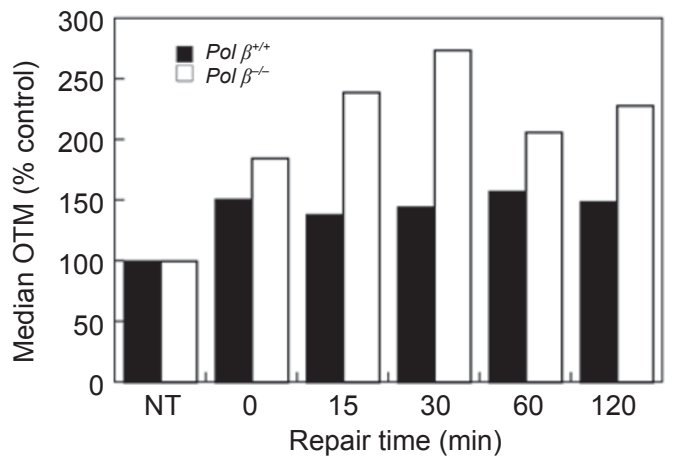

D

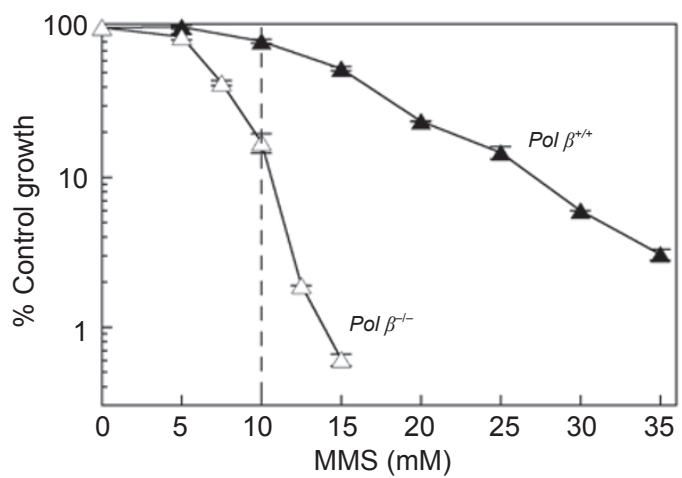

Figure 4 Increased DNA damage following exposure of repair-deficient mouse embryonic fibroblasts to MMS. (A and B) DNA damage (median OTM) after treatment of cells (as indicated) for $20 \mathrm{~min}$ with $10 \mathrm{mM}$ MMS in ice-cold medium, and then during repair in warm medium for up to $120 \mathrm{~min}$. NT are non-treated cells. (C) Sensitivity of $X R C C 1^{+/+}$(closed circles) and $X R C C 1^{-/}$ (open circles) and (D) Pol $\beta^{+/+}$(closed triangles), pol $\beta^{-\alpha}$ (open triangles) cells to a 20 min exposure to MMS in ice-cold medium. Growth inhibition assays were conducted as described [119]. Data are from representative experiments where the values are the mean \pm SEM of 3 independent determinations. The dashed line indicates the concentration of cold MMS used in the experiments presented in panels $\mathbf{A}$ and $\mathbf{B}$.

the ability of these cell types to directly repair MNNGinduced cytotoxic $\mathrm{O}^{6}$-methylguanine lesions by a process that is not dependent on cellular BER. XRCC1-deficient mouse fibroblasts are also significantly hypersensitive to the chemotherapeutic methylating agent temozolomide (TMZ) (Figure 2B, Table 2) and, like EM9 cells [93], they are extremely hypersensitive to 5-hydroxymethyl2 '-deoxyuridine (hmdUrd) (Figure 2C, Table 2). It is known that pol $\beta$-dependent BER is initiated following uracil-DNA glycosylase (SMUG1)-mediated removal of the abnormal base, hydroxymethyluracil, from cellular DNA [28]. Transfection with XRCC1 cDNA is able to fully rescue these hypersensitivity phenotypes of $X \mathrm{XCCl}^{-/}$cells (Figure 2B and 2C). Similar to MMS, $X R C C 1^{--}$fibroblasts are considerably more hypersensitive to these agents than are pol $\beta$ null BER-deficient mouse fibroblasts (Table 2) [28]. The hypersensitivity data obtained for hmdUrd in $X R C C 1^{--}$cells, as well as with the DNA methylating agents MMS, MNNG and TMZ, are consistent with the proposal that XRCC1 has a role in facilitating BER. In common between the methylating agents and hmdUrd is that BER of the resulting DNA lesions is initiated by a monofunctional glycosylase.

EM9 cells demonstrate only slight hypersensitivity $(<2$ fold) to bifunctional alkylating compounds that form DNA interstrand cross-links. Those tested include the clinically utilized agents mitomycin $\mathrm{C}$ and the nitrogen mustards melphalan and chlorambucil [56, 94, 95]. In contrast, $X R C C 1^{-/}$fibroblasts have significant hypersensitivity to monofunctional mustards that cannot cross-link DNA but instead result in formation of SSBs (Figure 5, panels A and B, Table 2). These compounds, 2-dimethylaminoethyl chloride (dimethyl mustard, DMM) and 2-diethylaminoethyl chloride (diethyl mustard, DEM) produce $N 7$-alkylguanine adducts in DNA [96]. Pol $\beta^{-/}$mouse fibroblasts also demonstrate hypersensitivity, but to a lesser extent ( 2-fold) (Table 2). The results suggest that these guanine adducts, although considerably more bulky than methylated DNA, are repaired at least in part by pol $\beta$-dependent BER. In support of this hypothesis, pamoic acid (PA), an inhibitor 

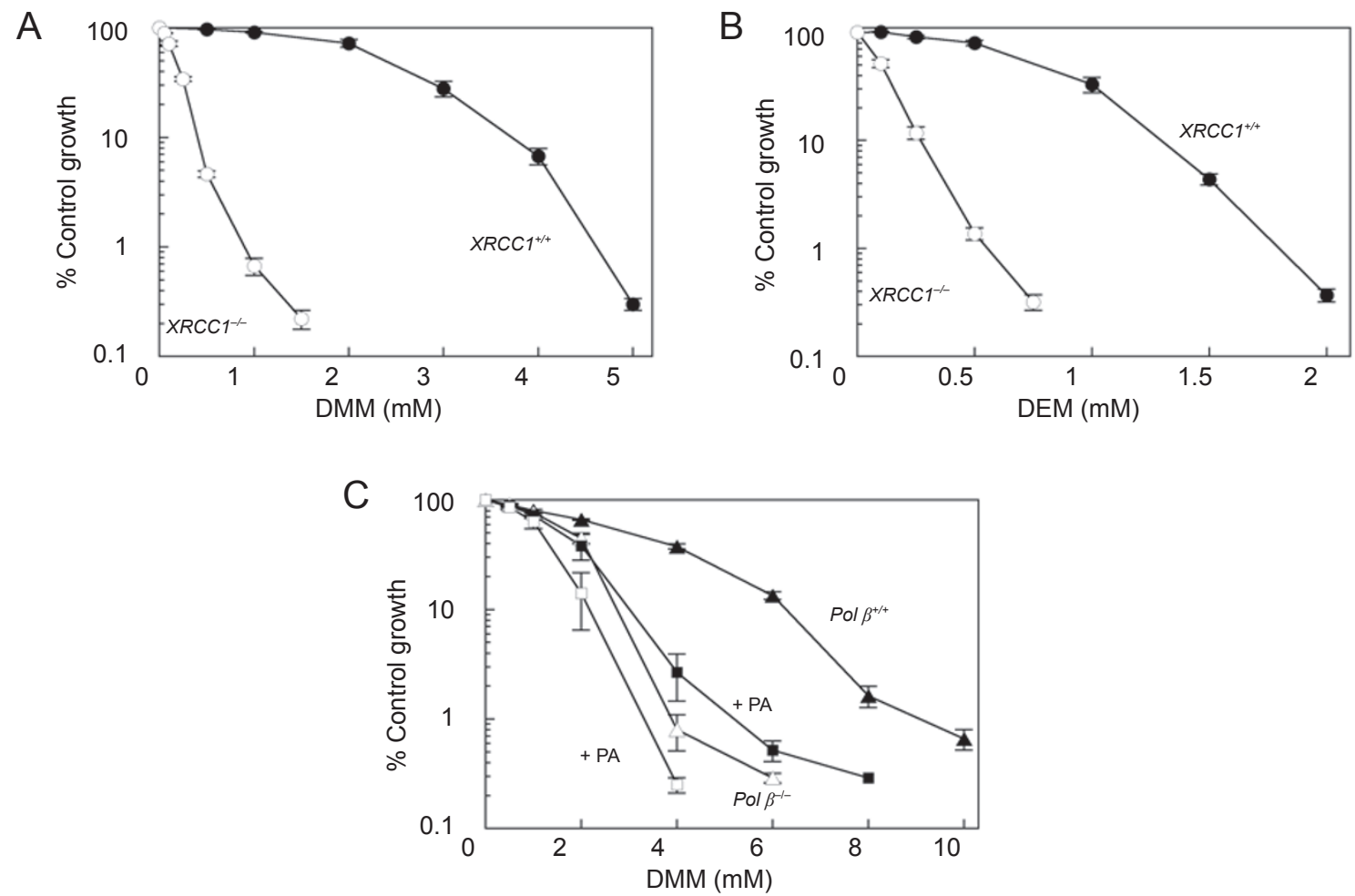

Figure $5 \mathrm{XRCC1}$ - and pol $\beta$-dependent hypersensitivity to monofunctional mustards. $X R C C 1^{+/+}$(closed circles) and $X R C C 1^{-/}$ (open circles) mouse embryonic fibroblasts were treated with (A) DMM or (B) DEM for $1 \mathrm{~h}$. (C) Pol $\beta^{+/+}$(closed symbols) and pol $\beta^{-\alpha}$ (open symbols) cells were treated with DMM for $1 \mathrm{~h}$ in the presence (squares) or absence (triangles) of pamoic acid (PA) (pretreatment with $300 \mu \mathrm{M}$ for $7 \mathrm{~h}$, then continued incubation following DMM for a total of $24 \mathrm{~h}$ ). Data represent the mean \pm SEM of at least 3 independent experiments. Cell sensitivity was determined by growth inhibition assays as described [119].

of pol $\beta$ [97], was able to significantly sensitize wild-type, but not pol $\beta^{-\alpha}$ fibroblasts to DMM- and DEM-induced cytotoxicity (Figure 5C).

Other types of bulky DNA adducts, such as those formed after exposure to UV or cisplatin, are generally considered to be repaired by nucleotide excision repair rather than BER. There is recent evidence that the XRCC1-ligase III $\alpha$ complex is required for ligation of breaks arising during nucleotide excision repair of UV lesions, but is indispensable only in quiescent cells [98]. However, neither XRCC1 mutant $\mathrm{CHO}$ cells $[57,95]$, nor $\mathrm{XRCC}^{-/-}$fibroblasts, are hypersensitive to UV-induced damage or cisplatin exposure when studies are conducted in proliferating cells (Table 2).

\section{Characteristics of XRCC1- and pol $\beta$-deficient cells: hypersensitivity to oxidative damage}

Despite the known interactions of XRCC1 with a number of other repair proteins (e.g., APE and PNK) that contribute activities required in each step of BER and SSBR (Table 1), $\mathrm{XRCCl}^{-/}$cells demonstrate only minimal hypersensitivity to the ROS-generating agents hydrogen peroxide and potassium bromate (Table 2). This result differs slightly from those obtained in XRCC1-defective $\mathrm{CHO}$ cells where a low (2-fold) hypersensitivity to hydrogen peroxide has been observed [99]. The lack of hypersensitivity to oxidative DNA damage is in contrast to the sizeable hypersensitivity to MMS and other methylating agents, and strongly suggests that oxidized and methylated DNA bases are repaired by different BER sub-pathways in $\mathrm{XRCCl}^{-/}$mouse fibroblasts. One potential difference will arise when oxidized bases are excised by bifunctional glycosylases, such as OGG1 with an associated lyase activity that cleaves the abasic site by $\beta$ elimination [12], or NEIL1 and 2 that cleave the abasic site by $\beta, \delta$-elimination $[13,14]$. During repair utilizing a bifunctional glycosylase, a $5^{\prime}$-dRP will not be formed and the dRP lyase activity of pol $\beta$ will not be required for repair (Table 1). Pol $\beta$ has been implicated in gap filling during repair of oxidative damage $[100,101]$, yet the initial characterization of pol $\beta$ null fibroblasts did not reveal a hydrogen peroxide hypersensitivity phenotype [26]. However, in older cells, low-level ( $<2$-fold) hypersensitivity to ROS agents was observed $[102,103]$. 
Characteristics of XRCC1- and pol $\beta$-deficient cells: hypersensitivity to Top1 inhibitors

Exposure of cells to camptothecin results in formation of SSBs with Top 1 covalently linked to the 3 '-termini. In CHO cells, XRCC1 has been shown to provide protection against the cytotoxicity of camptothecin [95, 104], and to enhance the repair of camptothecin-induced protein-linked SSBs [23]. Like XRCC1-deficient CHO cells, $\mathrm{XRCC1}^{-/}$mouse fibroblasts are moderately hypersensitive to camptothecin (Table 2) and expression of XRCC1 in $X R C C 1^{--}$fibroblasts can reverse the hypersensitivity phenotype (Figure 2D). This is in contrast to $\mathrm{pol} \beta^{-/}$cells that demonstrate negligible hypersensitivity to this Top1 inhibitor (Table 2).

The cellular hypersensitivity observed in the absence of XRCC1, but not in the absence of pol $\beta$, is consistent with the proposed mechanism for reversal of the proteinDNA complex. Repair requires hydrolysis of the covalent Top1-DNA phosphotyrosyl bond by Tdp1, and then endprocessing by PNK prior to DNA ligation, rather than pol $\beta$-dependent BER (Table 1). Tdp1 is critical for repair of this damage. It interacts both physically and functionally with XRCC1 [23], and it is known that Tdp1 activity at Top1-SSBs is stimulated by the XRCC1/ligase III $\alpha$ complex in vitro [9]. XRCC1 is also known to interact with PNK stimulating both the 3'-phosphatase and 5'-kinase activities at damaged termini, and acting to accelerate the overall rate of repair [38]. Interestingly, XRCC1-deficient mouse fibroblast cells are not hypersensitive to etoposide, an inhibitor of topoisomerase II (Table 2).

\section{Hypersensitivity phenotypes of XRCC1- and pol $\beta$ - deficient cells: role of PARP activity}

Characterization of XRCC1- and pol $\beta$-deficient cells has revealed an important role for both proteins in protection against the cytotoxic effects of agents resulting in DNA damage where repair is initiated by a monofunctional glycosylase (Table 2). Chemical inhibitors of PARP activity are able to enhance cell killing by these same agents that produce indirect strand breaks during BER. Specifically, exposure of wild-type and $\mathrm{pol} \beta^{-/}$cells to the potent PARP
A

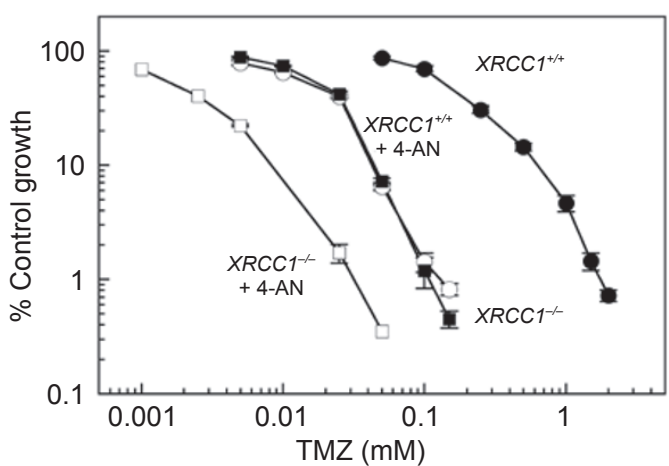

C

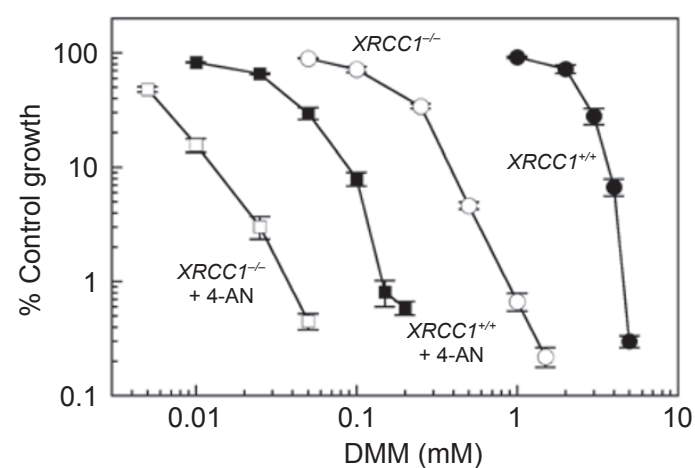

$\mathrm{B}$

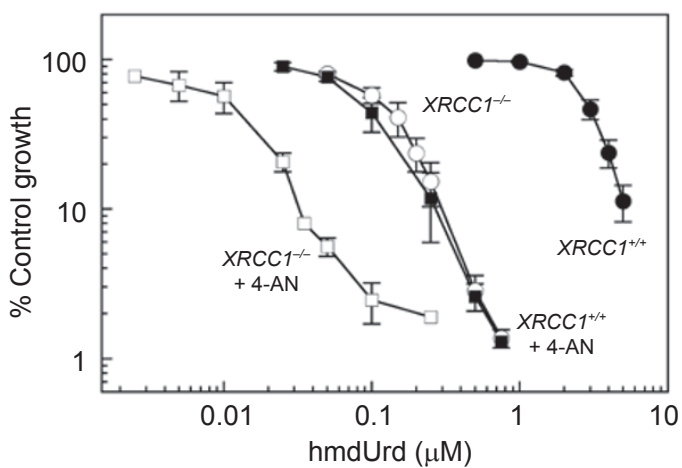

D

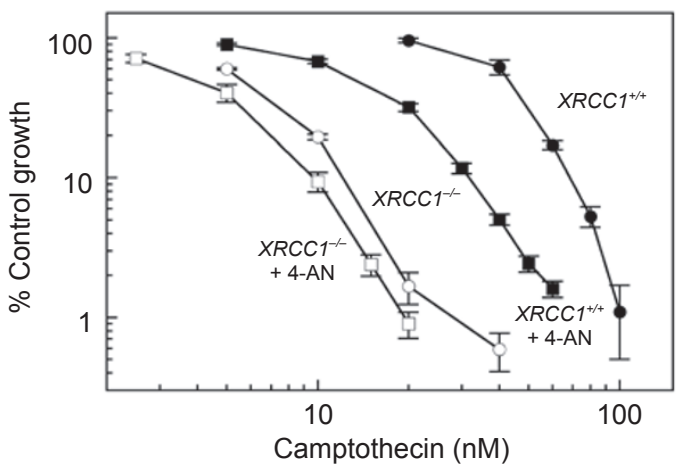

Figure 6 Hypersensitivity of $X R C C 1^{-/}$mouse embryonic fibroblasts to DNA damaging agents and effect of PARP inhibition. $X R C{ }^{1+/}$ (closed symbols) and XRCC1 $1^{-/}$cells (open symbols) were treated with (A) TMZ for $4 \mathrm{~h}$, (B) hmdUrd for $24 \mathrm{~h}$, (C) DMM for $1 \mathrm{~h}$ or (D) camptothecin for $24 \mathrm{~h}$. Shown are survival curves for 'control' cells in the absence of PARP inhibitor (circles), or cells treated in the presence of 4-AN $(5 \mu \mathrm{M}$ for $24 \mathrm{~h})$ (squares). Data represent the mean \pm SEM of at least 3 independent experiments. Cell sensitivity was determined by growth inhibition assays as described [119]. 
inhibitor, 4-amino-1,8-napthalimide (4-AN), is known to extremely sensitize them to the cytotoxic effects of $\mathrm{S}_{N} 2$ (e.g. MMS) and $\mathrm{S}_{N} 1$ (e.g. MNNG and TMZ) monofunctional methylating agents, as well as hmdUrd [105] (reviewed in [106]). For these agents, co-exposure to an inhibitor potentiates cytotoxicity in $\mathrm{pol} \beta^{--}$cells to a greater extent than in wild-type, thus resulting in an enhanced hypersensitivity phenotype. Results obtained in cell lines and animal models with the chemotherapeutic methylating agent TMZ have led to development of clinical trials of TMZ combined with a PARP inhibitor [107-109].

The BRCT I domain of XRCC1 capable of interacting with PARP-1 is critical for efficient SSBR and resistance to MMS-induced cytotoxicity $[52,91]$. It has been proposed that activation of PARP is required for recruitment of XRCC1 to sites of DNA damage. PAR synthesis by PARP-1 is known to recruit XRCC1 to repair foci in human and mouse fibroblasts, as well as HeLa cells [31, 53, 54]. Interestingly, sensitization to EMS by the PARP inhibitor 3-aminobenzamide was only slightly reduced in XRCC1-deficient EM9 compared with wild-type AA8 cells [110]. Similarly in mouse fibroblasts, PARP inhibition by 4-AN significantly sensitizes $X R C C 1^{-/}$cells to methylating agents and to DMM, although to a lesser extent than wild-type cells (Figure 6, Table 3). These data suggest that PARP-mediated poly(ADP-ribosyl) ation plays a role in modulation of cytotoxicity beyond recruitment of XRCC1 to sites of DNA damage. Since $X R C C 1^{--}$cells still exhibit significant hypersensitivity to all of the agents compared with $\mathrm{XRCCI}^{+/+}$cells when PARP activity is inhibited (i.e., in the presence of 4-AN), the results show that XRCC1 has a protective role in the cell in the absence of PARP activity (Figure 6).

A small 4-AN-mediated potentiation of camptothecin cytotoxicity was observed in $\mathrm{XRCCl}^{+/+}$cells, but the effect

Table 3 Sensitization by PARP inhibitor (4-AN)

\begin{tabular}{|c|c|c|}
\hline \multirow[t]{2}{*}{ DNA damaging agent } & \multicolumn{2}{|c|}{ PARP inhibition ${ }^{\mathrm{a}}$} \\
\hline & $X R C C 1^{+/+\mathrm{b}}$ & $X R C C 1^{-/ \mathrm{c}}$ \\
\hline \multicolumn{3}{|l|}{ Methylation } \\
\hline$-\operatorname{MMS}\left(\mathrm{S}_{N} 2\right)$ & 22 & 15 \\
\hline - MNNG $\left(\mathrm{S}_{N} 1\right)$ & 14 & 5 \\
\hline - TMZ $\left(\mathrm{S}_{N} 1\right)$ & 16 & 5 \\
\hline hmdUrd & 19 & 9 \\
\hline DMM & 42 & 32 \\
\hline IR & 2.0 & 1.6 \\
\hline Camptothecin & 2.3 & 1.3 \\
\hline
\end{tabular}

of 4-AN in $\mathrm{XRCCl}^{-/}$cells was extremely low (Figure 6D, Table 3). Similar results were reported when camptothecin was combined with a PARP inhibitor in wild-type and XRCC1-deficient CHO cells [111]. Sensitization to Top1 poisons by PARP inhibitors has been associated with persistence of DNA strand breaks as measured by the comet assay or alkaline elution $[111,112]$. Despite the relatively moderate sensitization to Top1 inhibitors compared with results obtained with monofunctional alkylating agents, there is interest in clinical evaluation of a topotecan/PARP inhibitor combination [109].

For IR, where there is only a minimal hypersensitivity phenotype in the absence of XRCC1 (Figure 1A), inhibition of PARP activity by 4-AN results in a comparatively low level (2-fold or less) sensitization even in $X R C C 1^{+/+}$cells (Table 3). It has been reported that PARP inhibitors are able to slow, but not prevent, sealing of IR-induced strand breaks in cells [113]. Presumably repair in the absence of PARP activity is sufficient to protect against IR-mediated cytotoxicity. In addition, only minimal PARP inhibitionmediated sensitization to oxidative DNA damaging agents was observed in wild-type mouse fibroblasts (reviewed in Ref. [106]).

It appears that extreme 4-AN-mediated sensitization is associated with the requirement for pol $\beta$-dependent $\mathrm{dRP}$ lyase activity during BER, and is observed for agents that exhibit a hypersensitivity phenotype in both XRCC1 and pol $\beta$ null cells (Table 2 ). This requirement for dRP lyasemediated repair is consistent with the observation that PARP-1 is activated specifically by strand break intermediates of this BER pathway [114].

\section{Characteristics of XRCC1- and pol $\beta$-deficient cells: repair deficiency following co-exposure to MMS and 4-AN}

PARP-1 is the first protein shown to interact with nicked DNA during BER [115], and failure to automodify results in inactivated PARP-1 remaining bound to damaged DNA. This may hinder access of repair proteins to sites of damage resulting in inhibition of SSBR [115] and accumulation of SSBs, especially in repair-deficient cells. In addition, blocked replication in response to inactivated PARP-1 protein bound to damaged DNA, and the subsequent delayed resolution of stalled replication forks [116], will result in generation of DSBs [117, 118].

It is therefore anticipated that the combination of MMS with a PARP inhibitor would result in an increased level of DNA strand breaks that could be measured by the alkaline comet assay. Cells $\left(X R C C 1^{+++}\right.$and $X R C C 1^{--}$, and $\mathrm{pol}$ $\beta^{+/+}$and $\mathrm{pol}^{---}$) were treated briefly with $1 \mathrm{mM}$ MMS in ice-cold medium in the presence or absence of 4-AN, and 
A

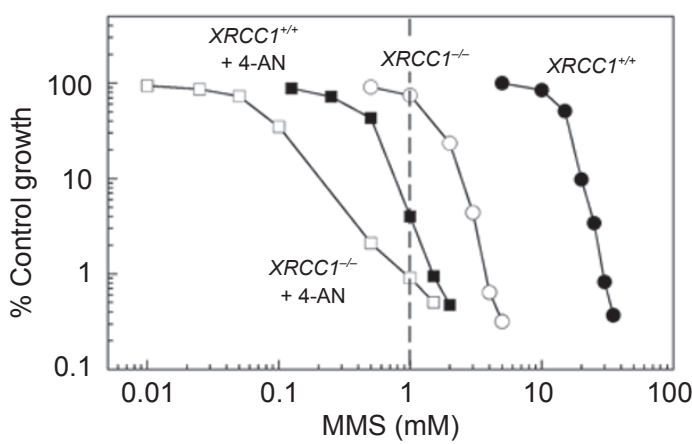

C

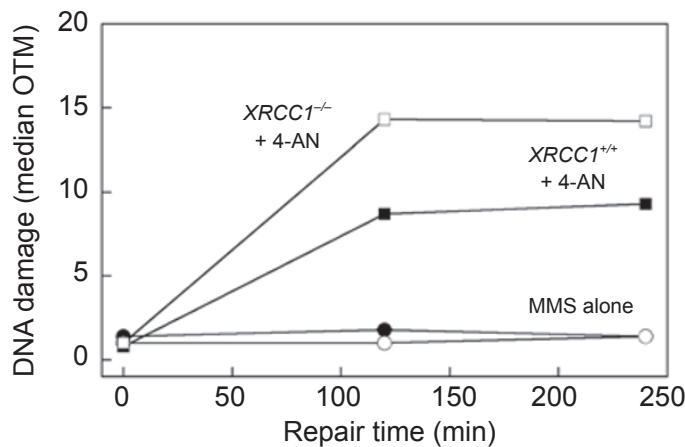

B

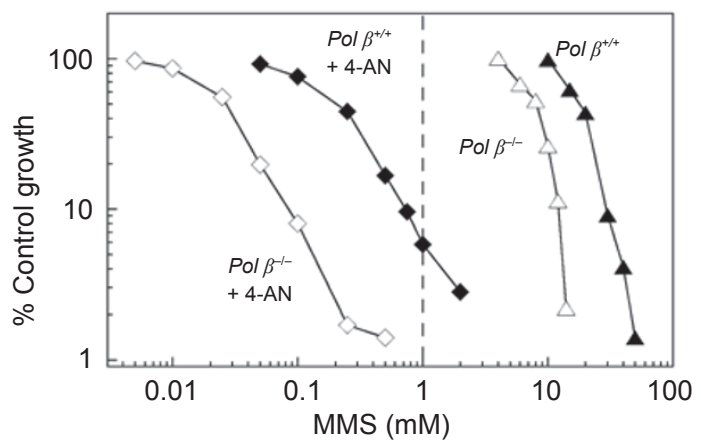

$\mathrm{D}$

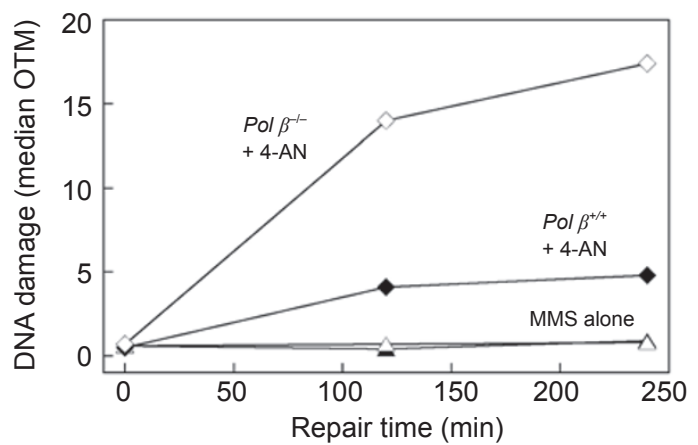

Figure 7 Enhanced cytotoxicity and increased DNA damage following co-exposure to MMS and 4-AN. (A) XRCC1 ${ }^{+/+}$(closed symbols) and $X R C C 1^{-/}$(open symbols) and (B) Pol $\beta^{+/+}$(closed symbols) and pol $\beta^{-/}$(open symbols) mouse embryonic fibroblasts were treated with MMS in ice-cold medium for $20 \mathrm{~min}$. Shown are survival curves for 'control' cells in the absence of PARP inhibitor (circles or triangles), or cells treated in the presence of 4-AN for a total of $24 \mathrm{~h}$ (squares or diamonds). Cell sensitivity was determined by growth inhibition assays as described [119]. Data are from a representative experiment where the values are the mean of triplicate determinations. The dashed line indicates the concentration of cold MMS combined with 4-AN used in the experiments presented in panels $\mathbf{C}$ and $\mathbf{D}$. (C) $X R C C 1^{+/+}$and $X R C C 1^{--}$and (D) $P O l \beta^{+/+}$and $p o l ~ \beta^{--}$cells were treated for 20 min with $1 \mathrm{mM}$ MMS in ice-cold medium in the absence or presence of 4-AN (symbols as described for panels $\mathbf{A}$ and $\mathbf{B}$ ). Plotted is DNA damage (median OTM) during cellular repair in warm medium \pm 4 -AN for up to $4 \mathrm{~h}$.

then allowed to repair in warm medium for up to $4 \mathrm{~h}$. When MMS was used as a single agent, no strand breaks were detectable in any of the four cell lines over the time course of the experiment (Figure 7, panels C and D). When MMS was combined with $4-\mathrm{AN}$, there was measurable damage in all of the cell variants. $X R C C 1^{--}$cells are less sensitized to MMS by 4-AN than are wild-type cells (Figure 7A, Table 3 ), yet retain a low level of hypersensitivity under conditions of PARP inhibition. A slightly higher level of DNA damage was observed in the XRCC1-deficient compared with $\mathrm{XRCC1}^{+/+}$cells in the presence of the PARP inhibitor (Figure 7C). Fibroblasts deficient in pol $\beta$ are more highly sensitized to MMS by 4-AN than are wild-type cells (Figure 7D) [105]. Levels of DNA damage were increased significantly more in the BER-deficient pol $\beta^{-/}$compared with wild-type cells following exposure to the combination of MMS + 4-AN (Figure 7D). The amplification of MMS-induced DNA damage in the presence of a PARP inhibitor is consistent with the level of PARP inhibition- mediated potentiation of MMS cytotoxicity in the cell lines studied.

\section{Concluding Remarks}

Both $\mathrm{XRCC}^{-/}$and $\mathrm{pol} \beta^{-/}$cells are most hypersensitive to agents that produce DNA lesions repaired by monofunctional glycosylase-initiated BER. These agents include the methylating agents MMS and TMZ, as well as the thymidine analog hmdUrd. Comet assay results support the hypothesis that $\mathrm{XRCC}^{-/}$cells, like pol $\beta^{-/}$cells, are deficient in cellular BER of MMS-induced damage. XRCC1 interacts with many proteins known to be involved in BER and SSBR. The PARP-interacting BRCT I domain of XRCC1 is critical in cells for efficient repair and resistance to MMS-induced cytotoxicity. PARP-1 is activated by direct SSBs in DNA, and also by indirect SSBs that arise during BER, and chemical inhibitors of PARP activity are able to enhance cell killing. The hypersensitivity phenotypes, as 
well as the extreme PARP inhibitor-mediated sensitization, are associated with a requirement for pol $\beta$-dependent $d R P$ lyase activity during repair. Even in the absence of XRCC1, PARP activity is a determinant of cell sensitivity to agents that produce DNA damage repaired by pol $\beta$-dependent BER. Thus PARP-mediated poly(ADP-ribosyl)ation plays a role in modulation of cytotoxicity beyond recruitment of $\mathrm{XRCC} 1$ to sites of DNA damage.

\section{Acknowledgements}

We thank our colleagues in the DNA Repair and Nucleic Acid Enzymology Group for their contributions. Special thanks are due to Dr William Beard and Dr Michelle Heacock for critical reading of the manuscript, and to Ms Jennifer Myers for editorial assistance. We thank Dr Robert Tebbs (Lawrence Livermore National Laboratory, currently at Applied Biosytems) for providing the XRCC1 mouse embryonic fibroblast cell lines. This research was supported by the Intramural Research Program of the NIH and NIEHS, USA.

\section{References}

1 Lindahl T. Instability and decay of the primary structure of DNA. Nature 1993; 362:709-715.

2 Srivastava DK, Vande Berg BJ, Prasad R, et al. Mammalian abasic site base excision repair. Identification of the reaction sequence and rate-determining steps. J Biol Chem 1998; 273:21203-21209.

3 Sossou M, Flohr-Beckhaus C, Schulz I, et al. APE1 overexpression in XRCC1-deficient cells complements the defective repair of oxidative single strand breaks but increases genomic instability. Nucleic Acids Res 2005; 33:298-306.

4 Ward JF. DNA damage produced by ionizing radiation in mammalian cells: identities, mechanisms of formation, and reparability. Prog Nucleic Acid Res Mol Biol 1988; 35:95-125.

5 Izumi T, Hazra TK, Boldogh I, et al. Requirement for human AP endonuclease 1 for repair of 3'-blocking damage at DNA singlestrand breaks induced by reactive oxygen species. Carcinogenesis 2000; 21:1329-1334.

6 Parsons JL, Dianova II, Dianov GL. APE1 is the major 3'-phosphoglycolate activity in human cell extracts. Nucleic Acids Res 2004; 32:3531-3536.

7 Takahashi T, Tada M, Igarashi S, et al. Aprataxin, causative gene product for EAOH/AOA1, repairs DNA single-strand breaks with damaged 3'-phosphate and 3'-phosphoglycolate ends. Nucleic Acids Res 2007; 35:3797-3809.

8 Jilani A, Ramotar D, Slack C, et al. Molecular cloning of the human gene, PNKP, encoding a polynucleotide kinase 3'-phosphatase and evidence for its role in repair of DNA strand breaks caused by oxidative damage. J Biol Chem 1999; 274:2417624186.

9 El-Khamisy SF, Hartsuiker E, Caldecott KW. TDP1 facilitates repair of ionizing radiation-induced DNA single-strand breaks. DNA Repair (Amst) 2007; 6:1485-1495.
10 Inamdar KV, Pouliot JJ, Zhou T, et al. Conversion of phosphoglycolate to phosphate termini on $3^{\prime}$ overhangs of DNA double strand breaks by the human tyrosyl-DNA phosphodiesterase hTdp1. J Biol Chem 2002; 277:27162-27168.

11 Ahel I, Rass U, El-Khamisy SF, et al. The neurodegenerative disease protein aprataxin resolves abortive DNA ligation intermediates. Nature 2006; 443:713-716.

12 Zharkov DO, Rosenquist TA, Gerchman SE, Grollman AP. Substrate specificity and reaction mechanism of murine 8-oxoguanine-DNA glycosylase. J Biol Chem 2000; 275:28607-28617.

13 Hazra TK, Izumi T, Boldogh I, et al. Identification and characterization of a human DNA glycosylase for repair of modified bases in oxidatively damaged DNA. Proc Natl Acad Sci USA 2002; 99:3523-3528.

14 Hazra TK, Kow YW, Hatahet Z, et al. Identification and characterization of a novel human DNA glycosylase for repair of cytosine-derived lesions. J Biol Chem 2002; 277:30417-30420.

15 Wiederhold L, Leppard JB, Kedar P, et al. AP endonucleaseindependent DNA base excision repair in human cells. Mol Cell Biol 2004; 15:209-220.

16 Vidal AE, Hickson ID, Boiteux S, Radicella JP. Mechanism of stimulation of the DNA glycosylase activity of hOGG1 by the major human AP endonuclease: bypass of the AP lyase activity step. Nucleic Acids Res 2001; 29:1285-1292.

17 Sung J-S, Demple B. Roles of base excision repair subpathways in correcting oxidized abasic sites in DNA. FEBS J 2006; 273:1620-1629.

18 Prasad R, Dianov GL, Bohr VA, Wilson SH. FEN1 stimulation of DNA polymerase $\beta$ mediates an excision step in mammalian long patch base excision repair. $J$ Biol Chem 2000; 275:44604466.

19 Liu Y, Beard WA, Shock DD, et al. DNA polymerase $\beta$ and flap endonuclease 1 enzymatic specificities sustain DNA synthesis for long patch base excision repair. J Biol Chem 2005; 280:36653674.

20 Fortini P, Pascucci B, Parlanti E, et al. Different DNA polymerases are involved in the short- and long-patch base excision repair in mammalian cells. Biochemistry 1998; 37:3575-3580.

21 Braithwaite EK, Prasad R, Shock DD, et al. DNA polymerase $\lambda$ mediates a back-up base excision repair activity in extracts of mouse embryonic fibroblasts. J Biol Chem 2005; 280:1846918475

22 Covey JM, Jaxel C, Kohn KW, Pommier Y. Protein-linked DNA strand breaks induced in mammalian cells by camptothecin, an inhibitor of topoisomerase I. Cancer Res 1989; 49:5016-5022.

23 Plo I, Liao ZY, Barcelo JM, et al. Association of XRCC1 and tyrosyl DNA phosphodiesterase (Tdp1) for the repair of topoisomerase I-mediated DNA lesions. DNA Repair (Amst) 2003; 2:1087-1100.

24 Strumberg D, Pilon AA, Smith M, et al. Conversion of topoisomerase I cleavage complexes on the leading strand of ribosomal DNA into 5'-phosphorylated DNA double-strand breaks by replication runoff. Mol Cell Biol 2000; 20:3977-3987.

25 Vens C, Hofland I, Begg AC. Involvement of DNA polymerase beta in repair of ionizing radiation damage as measured by in vitro plasmid assays. Radiat Res 2007; 168:281-291.

26 Sobol RW, Horton JK, Kuhn R, et al. Requirement of mammalian DNA polymerase- $\beta$ in base-excision repair. Nature 1996; 379:183-186. 
27 Sobol RW, Prasad R, Evenski A, et al. The lyase activity of the DNA repair protein $\beta$-polymerase protects from DNA-damageinduced cytotoxicity. Nature 2000; 405:807-810.

28 Horton JK, Joyce-Gray DF, Pachkowski BF, Swenberg JA, Wilson SH. Hypersensitivity of DNA polymerase $\beta$ null mouse fibroblasts reflects accumulation of cytotoxic repair intermediates from site-specific alkyl DNA lesions. DNA Repair (Amst) 2003; 2:27-48.

29 Marintchev A, Mullen MA, Maciejewski MW, et al. Solution structure of the single-strand break repair protein XRCC1 Nterminal domain. Nat Struct Biol 1999; 6:884-893.

30 Mani RS, Karimi-Busheri F, Fanta M, et al. Biophysical characterization of human XRCC1 and its binding to damaged and undamaged DNA. Biochemistry 2004; 43:16505-16514.

31 Lan L, Nakajima S, Oohata Y, et al. In situ analysis of repair processes for oxidative DNA damage in mammalian cells. Proc Natl Acad Sci USA 2004; 101:13738-13743.

32 Mortusewicz O, Leonhardt H. XRCC1 and PCNA are loading platforms with distinct kinetic properties and different capacities to respond to multiple DNA lesions. BMC Mol Biol 2007; 8:81.

33 Wong H-K, Wilson DM 3rd. XRCC1 and DNA polymerase $\beta$ interaction contributes to cellular alkylating-agent resistance and single-strand break repair. J Cell Biochem 2005; 95:794-804.

34 Mani RS, Fanta M, Karimi-Busheri F, et al. XRCC1 stimulates polynucleotide kinase by enhancing its damage discrimination and displacement from DNA repair intermediates. $\mathrm{J}$ Biol Chem 2007; 282:28004-28013.

35 Marsin S, Vidal AE, Sossou M, et al. Role of XRCC1 in the coordination and stimulation of oxidative DNA damage repair initiated by the DNA glycosylase hOGG1. J Biol Chem 2003; 278:44068-44074.

36 Campalans A, Marsin S, Nakabeppu Y, et al. XRCC1 interactions with multiple DNA glycosylases: a model for its recruitment to base excision repair. DNA Repair (Amst) 2005; 4:826-835.

37 Vidal AE, Boiteux S, Hickson ID, Radicella JP. XRCC1 coordinates the initial and late stages of DNA abasic site repair through protein-protein interactions. EMBO J 2001; 20:6530-6539.

38 Whitehouse CJ, Taylor RM, Thistlethwaite A, et al. XRCC1 stimulates human polynucleotide kinase activity at damaged DNA termini and accelerates DNA single-strand break repair. Cell 2001; 104:107-117.

39 Caldecott KW, Aoufouchi S, Johnson P, Shall S. XRCC1 polypeptide interacts with DNA polymerase $\beta$ and possibly poly (ADPribose) polymerase, and DNA ligase III is a novel molecular 'nick-sensor' in vitro. Nucleic Acids Res 1996; 24:4387-4394.

40 Kubota Y, Nash RA, Klungland A, et al. Reconstitution of DNA base excision-repair with purified human proteins: interaction between DNA polymerase $\beta$ and the XRCC1 protein. EMBO J 1996; 15:6662-6670.

41 Marintchev A, Robertson A, Dimitriadis EK, et al. Domain specific interaction in the XRCC1-DNA polymerase $\beta$ complex. Nucleic Acids Res 2000; 28:2049-2059.

42 Gryk MR, Marintchev A, Maciejewski MW, et al. Mapping of the interaction interface of DNA polymerase $\beta$ with XRCC1. Structure 2002; 10:1709-1720.

43 Taylor RM, Wickstead B, Cronin S, Caldecott KW. Role of a BRCT domain in the interaction of DNA ligase III- $\alpha$ with the DNA repair protein XRCC1. Curr Biol 1998; 8:877-880.
44 Luo H, Chan DW, Yang T, et al. A new XRCC1-containing complex and its role in cellular survival of methyl methanesulfonate treatment. Mol Cell Biol 2004; 24:8356-8365.

45 Date H, Igarashi S, Sano Y, et al. The FHA domain of aprataxin interacts with the $\mathrm{C}$-terminal region of XRCC1. Biochem Biophys Res Commun 2004; 325:1279-1285.

46 Clements PM, Breslin C, Deeks ED, et al. The ataxia-oculomotor apraxia 1 gene product has a role distinct from ATM and interacts with the DNA strand break repair proteins XRCC1 and XRCC4. DNA Repair (Amst) 2004; 3:1493-1502.

47 Masson M, Niedergang C, Schreiber V, et al. XRCC1 is specifically associated with poly(ADP-ribose) polymerase and negatively regulates its activity following DNA damage. $\mathrm{Mol}$ Cell Biol 1998; 18:3563-3571.

48 Schreiber V, Amé JC, Dolle P, et al. Poly(ADP-ribose) polymerase-2 (PARP-2) is required for efficient base excision DNA repair in association with PARP-1 and XRCC1. J Biol Chem 2002; 277:23028-23036.

49 Amé JC, Spenlehauer C, de Murcia G. The PARP superfamily. Bioessays 2004; 26:882-893.

50 Lindahl T, Satoh MS, Poirier GG, Klungland A. Post-translational modification of poly(ADP-ribose) polymerase induced by DNA strand breaks. Trends Biochem Sci 1995; 20:405-411.

51 D'Amours D, Desnoyers S, D’Silva I, Poirier GG. Poly(ADPribosyl)ation reactions in the regulation of nuclear functions. Biochem J 1999; 342:249-268.

52 Taylor RM, Thistlethwaite A, Caldecott KW. Central role for the XRCC1 BRCT I domain in mammalian DNA single-strand break repair. Mol Cell Biol 2002; 22:2556-2563.

53 El-Khamisy SF, Masutani M, Suzuki H, Caldecott KW. A requirement for PARP-1 for the assembly or stability of XRCC1 nuclear foci at sites of oxidative DNA damage. Nucleic Acids Res 2003; 31:5526-5533.

54 Okano S, Lan L, Caldecott KW, Mori T, Yasui A. Spatial and temporal cellular responses to single-strand breaks in human cells. Mol Cell Biol 2003; 23:3974-3981.

55 Leppard JB, Dong Z, Mackey ZB, Tomkinson AE. Physical and functional interaction between DNA ligase III $\alpha$ and poly(ADPribose) polymerase 1 in DNA single-strand break repair. $\mathrm{Mol}$ Cell Biol 2003; 23:5919-5927.

56 Thompson LH, Brookman KW, Dillehay LE, et al. A CHO-cell strain having hypersensitivity to mutagens, a defect in DNA strand-break repair, and an extraordinary baseline frequency of sister-chromatid exchange. Mutat Res 1982; 95:427-440.

57 Zdzienicka MZ, van der Schans GP, Natarajan AT, et al. A Chinese hamster ovary cell mutant (EM-C11) with sensitivity to simple alkylating agents and a very high level of sister chromatid exchanges. Mutagenesis 1992; 7:265-269.

58 Ochs K, Sobol RW, Wilson SH, Kaina B. Cells deficient in DNA polymerase $\beta$ are hypersensitive to alkylating agent-induced apoptosis and chromosomal breakage. Cancer Res 1999; 59:1544-1551.

59 Sobol RW, Kartalou M, Almeida KH, et al. Base excision repair intermediates induce $\mathrm{p} 53$-independent cytotoxic and genotoxic responses. J Biol Chem 2003; 278:39951-39959.

60 Nowak MA, Komarova NL, Sengupta A, et al. The role of chromosomal instability in tumor initiation. Proc Natl Acad Sci USA 2002; 99:16226-16231.

61 Hung RJ, Hall J, Brennan P, Boffetta P. Genetic polymorphisms 
in the base excision repair pathway and cancer risk: a HuGE review. Am J Epidemiol 2005; 162:925-942.

$62 \mathrm{Hu}$ Z, Ma H, Chen F, Wei Q, Shen H. XRCC1 polymorphisms and cancer risk: a meta-analysis of 38 case-control studies. Cancer Epidemiol Biomarkers Prev 2005; 14:1810-1808.

63 Sliwinski T, Ziemba P, Morawiec Z, et al. Polymorphisms of the DNA polymerase $\beta$ gene in breast cancer. Breast Cancer Res Treat 2007; 103:161-166.

64 Figueroa JD, Malats N, Real FX, et al. Genetic variation in the base excision repair pathway and bladder cancer risk. Hum Genet 2007; 121:233-242.

65 Starcevic D, Dalal S, Sweasy JB. Is there a link between DNA polymerase $\beta$ and cancer? Cell Cycle 2004; 3:998-1001.

66 Albertella MR, Lau A, O'Connor MJ. The overexpression of specialized DNA polymerases in cancer. DNA Repair (Amst) 2005; 4:583-593.

67 Thompson LH, Rubin JS, Cleaver JE, Whitmore GF, Brookman $\mathrm{K}$. A screening method for isolating DNA repair-deficient mutants of CHO cells. Somatic Cell Genet 1980; 6:391-405.

68 Shen MR, Zdzienicka MZ, Mohrenweiser H, Thompson LH, Thelen MP. Mutations in hamster single-strand break repair gene XRCC1 causing defective DNA repair. Nucleic Acids Res 1998; 26:1032-1037.

69 Thompson LH, Brookman KW, Minkler JL, et al. DNA-mediated transfer of a human DNA repair gene that controls sister chromatid exchange. Mol Cell Biol 1985; 5:881-884.

70 Thompson LH, Brookman KW, Jones NJ, Allen SA, Carrano AV. Molecular cloning of the human XRCC1 gene, which corrects defective DNA strand break repair and sister chromatid exchange. Mol Cell Biol 1990; 10:6160-6171.

71 Brookman KW, Tebbs RS, Allen SA, et al. Isolation and characterization of mouse $X r c c-1$, a DNA repair gene affecting ligation. Genomics 1994; 22:180-188.

72 Caldecott KW, Tucker JD, Stanker LH, Thompson LH. Characterization of the XRCC1-DNA ligase III complex in vitro and its absence from mutant hamster cells. Nucleic Acids Res 1995; 23:4836-4843.

73 Tebbs RS, Flannery ML, Meneses JJ, et al. Requirement for the Xrcc1 DNA base excision repair gene during early mouse development. Dev Biol 1999; 208:513-529.

74 Tebbs RS, Thompson LH, Cleaver JE. Rescue of Xrcc1 knockout mouse embryo lethality by transgene-complementation. DNA Repair (Amst) 2003; 2:1405-1417.

$75 \mathrm{Gu}$ H, Marth JD, Orban PC, Mossmann H, Rajewsky K. Deletion of a DNA polymerase $\beta$ gene segment in T cells using cell type-specific gene targeting. Science 1994; 265:103-106.

76 Sugo N, Aratani Y, Nagashima Y, Kubota Y, Koyama H. Neonatal lethality with abnormal neurogenesis in mice deficient in DNA polymerase $\beta$. EMBO J 2000; 19:1397-1404.

77 Sugo N, Niimi N, Aratani Y, Takiguchi-Hayashi K, Koyama H. p53 Deficiency rescues neuronal apoptosis but not differentiation in DNA polymerase $\beta$-deficient mice. Mol Cell Biol 2004; 24:9470-9477.

78 Raaphorst GP, Ng CE, Yang DP. Comparison of response to radiation, hyperthermia and cisplatin in parental and polymerase $\beta$ knockout cells. Int J Hyperthermia 2002; 18:33-39.

79 Ward JF. Complexity of damage produced by ionizing radiation. Cold Spring Harb Symp Quant Biol 2000; 65:377-382.

80 Singh NP, McCoy MT, Tice RR, Schneider EL. A simple tech- nique for quantitation of low levels of DNA damage in individual cells. Exp Cell Res 1988; 175:184-191.

81 Olive PL, Banath JP, Durand RE. Heterogeneity in radiationinduced DNA damage and repair in tumor and normal cells measured using the "comet" assay. Radiat Res 1990; 122:8694.

82 Vilenchik MM, Knudson AG. Radiation dose-rate effects, endogenous DNA damage, and signaling resonance. Proc Natl Acad Sci USA 2006; 103:17874-178779.

83 Nocentini S. Rejoining kinetics of DNA single- and double-strand breaks in normal and DNA ligase-deficient cells after exposure to ultraviolet $\mathrm{C}$ and gamma radiation: an evaluation of ligating activities involved in different DNA repair processes. Radiat Res 1999; 151:423-432.

84 Loizou JI, El-Khamisy SF, Zlatanou A, et al. The protein kinase CK2 facilitates repair of chromosomal DNA single-strand breaks. Cell 2004; 117:17-28.

85 Chappell C, Hanakahi LA, Karimi-Busheri F, Weinfeld M, West $\mathrm{SC}$. Involvement of human polynucleotide kinase in doublestrand break repair by non-homologous end joining. EMBO J 2002; 21:2827-2832.

86 Audebert M, Salles B, Calsou P. Involvement of poly(ADP-ribose) polymerase-1 and XRCC1/DNA ligase III in an alternative route for DNA double-strand breaks rejoining. J Biol Chem 2004; 279:55117-55126.

87 Audebert M, Salles B, Weinfeld M, Calsou P. Involvement of polynucleotide kinase in a poly(ADP-ribose) polymerase-1dependent DNA double-strand breaks rejoining pathway. $J$ Mol Biol 2006; 356:257-265.

88 Lévy N, Martz A, Bresson A, et al. XRCC1 is phosphorylated by DNA-dependent protein kinase in response to DNA damage. Nucleic Acids Res 2006; 34:32-41.

89 Vermeulen C, Verwijs-Janssen M, Cramers P, Begg AC, Vens C. Role for DNA polymerase beta in response to ionizing radiation. DNA Repair (Amst) 2007; 6:202-212.

90 Taylor RM, Moore DJ, Whitehouse J, Johnson P, Caldecott KW. A cell cycle-specific requirement for the XRCC1 BRCT II domain during mammalian DNA strand break repair. Mol Cell Biol 2000; 20:735-740.

91 Kubota Y, Horiuchi S. Independent roles of XRCC1's two BRCT motifs in recovery from methylation damage. DNA Repair (Amst) 2003; 2:407-415.

92 Barrows LR, Paxton MB, Kennedy KA, Thompson LH. Characterization of revertants of the CHO EM9 mutant arising during DNA transfection. Carcinogenesis 1991; 12:805-811.

93 Fan J, Wilson PF, Wong HK, et al. XRCC1 down-regulation in human cells leads to DNA-damaging agent hypersensitivity, elevated sister chromatid exchange, and reduced survival of BRCA2 mutant cells. Environ Mol Mutagen 2007; 48:491500.

94 Hoy CA, Thompson LH, Mooney CL, Salazar EP. Defective DNA cross-link removal in Chinese hamster cell mutants hypersensitive to bifunctional alkylating agents. Cancer Res 1985; 45:1737-1743.

95 Caldecott K, Jeggo P. Cross-sensitivity of $\gamma$-ray-sensitive hamster mutants to cross-linking agents. Mutat Res 1991; 255:111121.

96 Price CC, Gaucher GM, Koneru P, et al. Relative reactivities for monofunctional nitrogen mustard alkylation of nucleic acid 
components. Biochim Biophys Acta 1968; 166:327-359.

$97 \mathrm{Hu} \mathrm{HY}$, Horton JK, Gryk MR, et al. Identification of small molecule synthetic inhibitors of DNA polymerase $\beta$ by NMR chemical shift mapping. J Biol Chem 2004; 279:39736-39744.

98 Moser J, Kool H, Giakzidis I, et al. Sealing of chromosomal DNA nicks during nucleotide excision repair requires XRCC1 and DNA ligase III $\alpha$ in a cell-cycle-specific manner. Mol Cell 2007; 27:311-323.

99 Dianova II, Sleeth KM, Allinson SL, et al. XRCC1-DNA polymerase $\beta$ interaction is required for efficient base excision repair. Nucleic Acids Res 2004; 32:2550-2555.

100 Dianov G, Bischoff C, Piotrowski J, Bohr VA. Repair pathways for processing of 8-oxoguanine in DNA by mammalian cell extracts. J Biol Chem 1998; 273:33811-33816.

101 Fortini P, Parlanti E, Sidorkina OM, Laval J, Dogliotti E. The type of DNA glycosylase determines the base excision repair pathway in mammalian cells. J Biol Chem 1999; 274:1523015236.

102 Fortini P, Pascucci B, Belisario F, Dogliotti E. DNA polymerase $\beta$ is required for efficient DNA strand break repair induced by methyl methanesulfonate but not by hydrogen peroxide. Nucleic Acids Res 2000; 28:3040-3046.

103 Horton JK, Baker A, Vande Berg BJ, Sobol RW, Wilson SH. Involvement of DNA polymerase $\beta$ in protection against the cytotoxicity of oxidative damage. DNA Repair (Amst) 2002; 1:317-333.

104 Barrows LR, Holden JA, Anderson M, D’Arpa P. The CHO XRCC1 mutant, EM9, deficient in DNA ligase III activity, exhibits hypersensitivity to camptothecin independent of DNA replication. Mutat Res 1998; 408:103-110.

105 Horton JK, Stefanick DF, Naron JM, Kedar PS, Wilson SH. Poly(ADP-ribose) polymerase activity prevents signaling pathways for cell cycle arrest following DNA methylating agent exposure. J Biol Chem 2005; 280:15773-15785.

106 Horton JK, Wilson SH. Hypersensitivity phenotypes associated with genetic and synthetic inhibitor-induced base excision repair deficiency. DNA Repair (Amst) 2007; 6:530-543.

107 Tentori L, Graziani G. Chemopotentiation by PARP inhibitors in cancer therapy. Pharmacol Res 2005; 52:25-33.

108 Plummer ER. Inhibition of poly(ADP-ribose) polymerase in cancer. Curr Opin Pharmacol 2006; 6:364-368.

109 Thomas HD, Calabrese CR, Batey MA, et al. Preclinical se- lection of a novel poly(ADP-ribose) polymerase inhibitor for clinical trial. Mol Cancer Ther 2007; 6:945-956.

110 Ikejima M, Bohannon D, Gill DM, Thompson LH. Poly(ADPribose) metabolism appears normal in EM9, a mutagen-sensitive mutant of CHO cells. Mutat Res 1984; 128:213-220.

111 Smith LM, Willmore E, Austin CA, Curtin NJ. The novel poly(ADP-Ribose) polymerase inhibitor, AG14361, sensitizes cells to topoisomerase I poisons by increasing the persistence of DNA strand breaks. Clin Cancer Res 2005; 11:8449-8457.

112 Miknyoczki S, Chang H, Grobelny J, et al. The selective poly(ADP-ribose) polymerase-1(2) inhibitor, CEP-8983, increases the sensitivity of chemoresistant tumor cells to temozolomide and irinotecan but does not potentiate myelotoxicity. Mol Cancer Ther 2007; 6:2290-2302.

113 Zwelling LA, Kerrigan D, Pommier Y. Inhibitors of poly-(adenosine diphosphoribose) synthesis slow the resealing rate of x-ray-induced DNA strand breaks. Biochem Biophys Res Commun 1982; 104:897-902.

114 Lavrik OI, Prasad R, Sobol RW, et al. Photoaffinity labeling of mouse fibroblast enzymes by a base excision repair intermediate. Evidence for the role of poly (ADP-ribose) polymerase-1 in DNA repair. J Biol Chem 2001; 276:25541-25548.

115 Parsons JL, Dianova II, Allinson SL, Dianov GL. Poly(ADPribose) polymerase-1 protects excessive DNA strand breaks from deterioration during repair in human cell extracts. FEBS $J$ 2005; 272:2012-2021.

116 Yang Y-G, Cortes U, Patnaik S, Jasin M, Wang Z-Q. Ablation of PARP-1 does not interfere with the repair of DNA double-strand breaks, but compromises the reactivation of stalled replication forks. Oncogene 2004; 23:3872-3882.

117 Arnaudeau C, Lundin C, Helleday T. DNA double-strand breaks associated with replication forks are predominantly repaired by homologous recombination involving an exchange mechanism in mammalian cells. J Mol Biol 2001; 307:1235-1245.

118 Haince J-F, Rouleau M, Hendzel MJ, Masson J-Y, Poirier GG. Targeting poly(ADP-ribosyl)ation: a promising approach in cancer therapy. Trends Mol Med 2005; 11:456-463.

119 Horton JK, Prasad R, Hou E, Wilson SH. Protection against methylation-induced cytotoxicity by DNA polymerase $\beta$-dependent long patch base excision repair. J Biol Chem 2000; 275:2211-2218. 